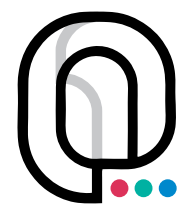

Asociación de Internet.mx

\title{
IA: MÁQUINAS INTELIGENTES, POLÍTICAS INTELIGENTES
} RESUMEN DE LA CONFERENCIA

\section{DOCUMENTOS SOBRE ECONOMÍA DIGITAL DE LA OCDE} Agosto 2018 Núm. 270 
Este documento contiene un resumen de los procedimientos de la conferencia titulada "Inteligencia Artificial (IA), Máquinas Inteligentes, Políticas Inteligentes" celebrada en las oficinas centrales de la Organización para la Cooperación y el Desarrollo Económicos (OCDE) en París, Francia, los días 26 y 27 de octubre de 2017. El Comité sobre Política en Economía Digital lo aprobó y desclasificó el 18 de mayo de 2018 y lo preparó para su publicación a través de la Dirección de la OCDE.

Esta traducción se publica por acuerdo con la OCDE. No es una traducción oficial de la OCDE. La calidad de la traducción y su coherencia con el texto del idioma original de la obra son responsabilidad exclusiva del autor (es) de la traducción. En el caso de cualquier discrepancia entre el trabajo original y la traducción, solo el texto del trabajo original se considerará válido.

Publicado originalmente por la OCDE en inglés bajo el título: OECD (2018), "AI: Intelligent machines, smart policies: Conference summary", OECD Digital Economy Papers, No. 270, OECD Publishing, París, https://doi.org/10.1787/fla650d9-en (C) 2019 Asociación Mexicana de Internet, A.C. para esta edición en español.

Este documento, así como todos los datos y mapas aquí incluidos, se entenderán sin prejuicio respecto al estatus o soberanía de cualquier territorio, a la delimitación de las fronteras y límites internacionales ni al nombre de cualquier territorio, ciudad o área. 


\section{Prólogo}

Este documento contiene un resumen de los procedimientos de la conferencia titulada "IA: Máquinas inteligentes, Políticas Inteligentes", celebrada en las oficinas centrales de la OCDE en París Francia, el 26 y 27 de octubre de 2017. Karine Perset y Nobuhisa Nishigata del secretariado de la OCDE lo redactaron con la participación de Claire Jolly, Stijn Broecke y Anne Carblanc. Los ponentes revisaron el borrador y proporcionaron información y correcciones.

El equipo organizador del evento incluyó, de la división sobre Política en Economía Digital de la Dirección de la OCDE para Ciencia, Tecnología e Innovación (STI, por sus siglas en inglés) -en orden alfabético- Brigitte Acoca, Sarah Ferguson, Anna-Sophie Liebender, Nobuhisa Nishigata, Elettra Ronchi, Cristina Serra-Vallejo, Yuki Yokomori, con la coordinación total de Karine Perset. Claire Jolly y Alistair Nolan de la división de STI sobre Política de Ciencia y Tecnología y Stijn Broecke de la Dirección de la OCDE para Empleo, Trabajo y Asuntos Sociales se encargaron de la organización conjunta del evento. Se agradecen las contribuciones de Shayne MacLachlan de la Dirección de Comunicación y Asuntos Públicos de la OCDE y de Suzanna Grant-Kejairi de la Dirección Ejecutiva de la OCDE. Anne Carblanc, Jefa de la División sobre Política de Economía Digital; Andrew Wyckoff, Director de Ciencia, Tecnología e Innovación de la OCDE y Douglas Frantz, Secretario General Adjunto proporcionaron liderazgo y supervisión.

El Ministerio de Asuntos Internos y Comunicaciones (MIC, por sus siglas en inglés) de Japón patrocinó la conferencia. Reunió a representantes de la sociedad civil, planificadores de políticas, expertos en IA de la industria y academia para discutir las oportunidades y retos, así como el papel de la política y cooperación internacional. El evento atrajo a 50 ponentes y 300 participantes. Participaron delegados gubernamentales de diversos dominios, incluyendo ministros de economía digital, ministros de trabajo, representantes de la agencia espacial, ministros de investigación, autoridades para la protección de datos y agencia de protección al consumidor.

Google Arts \& Culture y Facebook proporcionaron demostraciones interactivas. Google Arts $\&$ Culture mostró experimentos de aprendizaje automático en exhibiciones de arte resultado de su colaboración con más de 1200 museos, galerías e instituciones internacionales de 70 países, disponibles a través de la aplicación en línea (https://artsandculture.google.com/). Facebook mostró el "Facebook 360 Innovation Tour" para presentar sus tecnologías de realidad virtual e IA más recientes con Samsung Gear VR impulsados por Oculus.

Más información, incluyendo presentaciones e imágenes, está disponible en http://oe.cd/ai. 


\section{Presentación a la edición en español}

Para la Asociación de Internet MX, la inteligencia artificial tiene una enorme capacidad transformadora. Creemos que es una de las apuestas más prometedoras de la humanidad para afrontar los desafíos del futuro: el cambio climático; la preservación y recuperación de ecosistemas; el aprovechamiento óptimo de recursos; la prestación de servicios de salud pública universal; lograr una economía mundial con mejor distribución de la riqueza, por mencionar solo algunos.

De la mano de los enormes beneficios de la inteligencia artificial, vienen retos y responsabilidades de la misma dimensión. Por ejemplo, los sistemas educativos requieren proveer a los estudiantes de nuevas habilidades; en el mercado laboral, diversos empleos dejan de ser necesarios y surgen otros; la demanda de procesamiento de datos exige estándares globales de privacidad y seguridad de la información; o las normas legales de responsabilidad y propiedad intelectual se ponen a prueba en un entorno donde los creadores de inteligencia artificial también son sistemas algorítmicos.

¿Qué tipo de políticas públicas son necesarias para que las sociedades y sus economías promuevan el desarrollo, y se beneficien de la inteligencia artificial, de una forma incluyente, responsable y segura?

Esta pregunta nos parece de la mayor trascendencia; y naturalmente su respuesta no puede venir de una sola fuente, sino del conjunto de actores varios de la sociedad, en sus ámbitos económico, político, social o académico, en un contexto de cooperación internacional.

De ella se ha ocupado la conferencia "Inteligencia artificial: máquinas inteligentes, políticas inteligentes" (AI: Intelligent Machines, Smart Policies), celebrada bajo el auspicio de la Organización para la Cooperación y el Desarrollo Económicos. Nos enorgullecemos de presentar la traducción al español del resumen ejecutivo de la conferencia.

No tenemos duda de que la valiosa aportación de los participantes, reflejada en la minuciosa calidad del resumen, será un insumo muy útil para el diseño de políticas públicas y la continua conversación y cooperación internacional en la materia.

Traducción al español patrocinada por Microsoft Corporation, Google Inc. y Facebook Inc. 
Indice

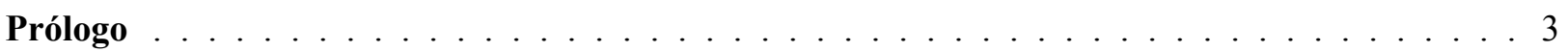

Presentación a la edición en español $\ldots \ldots \ldots \ldots \ldots \ldots \ldots \ldots$

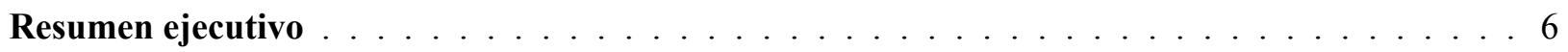

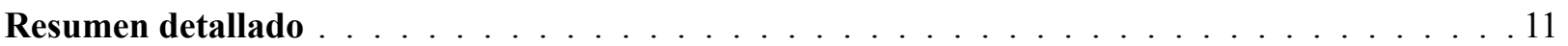

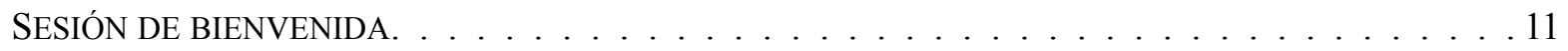

SESIÓN 1: EL ESTADO DE LA INVESTIGACIÓN DE LA IA. . . . . . . . . . . . . . . 12

SESIÓN 2: ESTUDIOS DE CASOS Y APLICACIONES DE LA IA . . . . . . . . . . . . . . 15

SESIÓN 3: ACERCAMIENTO A LA IA EN APLICACIONES ESPACIALES . . . . . . . . . . . . . 17

SESIÓN 4: MEJORAR LOS DESCUBRIMIENTOS - EL PAPEL DE LA IA EN LA CIENCIA. . . . . . . . 18

SESIÓN 5: EL PANORAMA DE LAS POLÍTICAS DE IA . . . . . . . . . . . . . . . 21

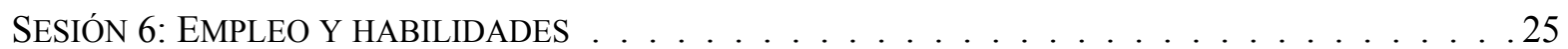

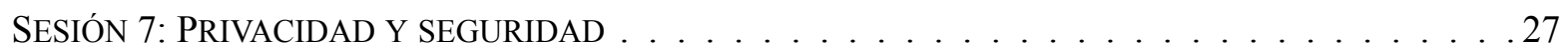

SESIÓN 8: SEGURIDAD, RESPONSABILIDAD LEGAL Y DE CUALQUIER OTRA ÍNDOLE . . . . . . . 29

SESIÓN 9: TRANSPARENCIA, SUPERVISIÓN Y ÉTICA . . . . . . . . . . . . . . . . . 31

SESIÓN 10: CIERRE Y PASOS SIGUIENTES . . . . . . . . . . . . . . . . . . . 34

Anexo. Agenda de la Conferencia . . . . . . . . . . . . . . . . . . . . . . . . . . 39 


\section{Resumen ejecutivo}

Este informe refleja las presentaciones e intercambios que tuvieron lugar en la conferencia de la OCDE “IA: Máquinas Inteligentes, Políticas Inteligentes”. La conferencia contó con 50 ponentes y 300 tecnólogos, planificadores de políticas de alto nivel y representantes de la sociedad civil, trabajadores y empresas ante la OCDE en París el 26 y 27 de octubre de 2017 (http://oe.cd/ai).

La discusión se centró en una respuesta de políticas coordinadas en torno a la transformación de la sociedad, gobierno e industria impulsada por los sistemas de inteligencia artificial (IA). Los objetivos de la conferencia consistieron en promover un intercambio vigoroso entre planificadores de políticas, investigadores, académicos y el público, informar sobre el trabajo hacia el futuro del proyecto "Going Digital" de la OCDE e informar del trabajo que realiza en materia de políticas para la inteligencia artificial que ayudarán a crear una prosperidad ampliamente compartida y a desbloquear nuevas oportunidades para el progreso en áreas críticas como la salud, educación y el medio ambiente.

\section{La IA está transformando los sectores sociales y económicos de forma más profunda y rápida de lo esperado}

La IA no es ciencia ficción ni un proyecto escolar de ciencia. Se llegó al consenso universal con respecto a que la inteligencia ya ofrece aplicaciones beneficiosas que gente de todo el mundo utiliza diariamente. Conforme avanzó, los participantes de la conferencia sugirieron que el desarrollo y los usos de los sistemas de IA deben guiarse por principios que promuevan el bienestar y la prosperidad mientras protegen los derechos individuales y la democracia.

Surgió un consenso en torno a que los cambios acelerados y de gran alcance de la IA ofrecen oportunidades dinámicas para mejorar los sectores económicos y sociales. La IA puede crear negocios más productivos, mejorar la eficiencia gubernamental y liberar a los trabajadores de tareas mundanas. También puede aplicarse a la mayoría de nuestros problemas globales más apremiantes como el cambio climático y el acceso más amplio a la educación y a la atención médica.

\section{La IA está avanzando rápidamente, y por ello, los gobiernos también lo deben hacer}

La política sobre IA es un asunto urgente. Los ponentes señalaron que el desarrollo de la IA se encuentra en un punto crucial. El ritmo acelerado de la investigación en IA, junto con la rapidez de su implementación en el mundo real reduce dramáticamente el periodo y la distinción entre la investigación fundamental y el impacto de la IA en el trabajo y el juego. Impulsado por la investigación del sector privado, el salto del laboratorio a la oficina o la fábrica ha disminuido progresivamente en los últimos cinco años. Estos factores acentúan la necesidad de un compromiso oportuno y sólido entre el gobierno, industria, política y expertos técnicos y el público.

Un tema recurrente fue el potencial de la IA para incrementar la eficiencia y efectividad de todos los sectores, incluyendo el suministro de servicios públicos. Aplicada de forma inteligente, la IA puede mejorar el bienestar de la sociedad en áreas como la educación, 
seguridad pública, salud y equilibrio entre la vida laboral y la familiar. Los gobiernos necesitan planificar para invertir en y desarrollar la IA para obtener sus muchos beneficios.

\section{Se necesitan nuevas políticas que permitan adoptar la IA en el lugar de trabajo}

Otro enfoque clave fue el papel de la IA para definir el futuro del trabajo. La IA está asumiendo algunas tareas realizadas durante mucho tiempo por los seres humanos. Estos cambios crearán nuevas oportunidades en el lugar de trabajo y en el equilibrio entre la vida laboral y la familiar. Pero dichos cambios también tendrán un impacto en las ocupaciones de millones de personas. El aprendizaje profundo, apoyado por el aprendizaje de refuerzo, recientemente ha llevado a avances impresionantes en la capacidad de la IA. Hoy en día, el rendimiento de la IA es superior al rendimiento humano: entre 2010 y 2017, la exactitud de reconocimiento de la imagen creció supuestamente de $70 \%$ a $96 \%$; la exactitud del rendimiento humano permaneció a 95\%.

Había incertidumbre acerca de la rapidez y la escala de la transición, no obstante, hubo un consenso en que los gobiernos deberán adaptar políticas existentes y desarrollar nuevas estrategias que preparen a los ciudadanos, educadores y comerciantes para los trabajos del futuro y minimicen los impactos negativos. Se hizo hincapié en la educación y capacitación de trabajadores que ingresan a la fuerza laboral y capacitar nuevamente a los desplazados por la IA.

Además del impacto de la automatización y robótica en la fuerza de trabajo, diversos participantes comentaron que los gobiernos y empresas deben cooperar para crear políticas con el fin de garantizar que la IA no extienda las divisiones económicas entre la gente, compañías de diferentes tamaños, países y continentes. Las políticas y programas se delinearon para minimizar la extensa ruptura económica y para proporcionar un acceso más amplio a las tecnologías de IA, para ayudar especialmente a las pequeñas y medianas empresas (PyME) a navegar en la transición de la IA. Las inversiones dirigidas en I+D, el acceso a los datos y el aprendizaje de habilidades especiales estuvieron entre las herramientas destacadas para proporcionar un amplio acceso a la IA para compañías y sectores en peligro de quedarse rezagadas.

De manera similar, los participantes expresaron su preocupación acerca de la concentración de la tecnología y los recursos financieros en las manos de unas cuantas compañías y naciones. La noción de los mercados "el ganador toma todo" se marcó como un asunto clave. A los representantes laborales les preocupó el impacto en la autonomía del trabajador de los mecanismos de ahorro de costos y el incremento de la productividad en las compañías de IA dominantes. Las grandes compañías explicaron cómo están tratando de abordar estos asuntos. Por ejemplo, Google distribuye gratuitamente su tecnología de aprendizaje automático, así como algunos conjuntos de datos de capacitación.

Se expresaron asuntos relacionados acerca de la escasez de trabajadores capacitados y de la dificultad de las pequeñas firmas y el sector público para competir con las firmas dominantes por el escaso talento. Sin trabajadores capacitados, las PyME y las agencias públicas corren el riesgo de quedarse rezagadas. Diversos participantes europeos mencionaron que compartir los beneficios de la IA en Europa se restringe por el flujo de investigadores e ingenieros a otras regiones y la migración del sector público al sector privado. Otros mencionaron que los ingenieros informáticos de IA más brillantes a menudo son contratados por organizaciones impulsadas por los ingresos con salarios lucrativos en lugar de afrontar retos sociales importantes a través de la investigación y del trabajo del sector púbico. 


\section{Obtener beneficios de la IA requiere un acceso mejorado a los datos}

La dependencia de la IA a vastas cantidades de datos crea asuntos técnicos, culturales y legales complejos que rodean la protección de datos, la regulación y la economía de los mismos. Uno de los temas más fuertes que surgió de la conferencia fue la necesidad de mejorar el acceso a los datos para utilizar la IA ampliamente a través de una política de datos abierta, la interoperabilidad de datos y la normalización del formato de datos, así como un mejor manejo de los datos personales. Las tecnologías de aprendizaje automático actuales requieren datos precisos, seleccionados y organizados "curados" para permitir a las compañías, institutos de investigación y al sector público crear productos y servicios innovadores. Por ejemplo, los participantes acreditaron la grandiosa innovación llevada a cabo en el sector satelital a las políticas de datos abiertos para los datos satelitales de entidades públicas como la NASA o Copernicus.

Las aplicaciones de la IA en la observación de la tierra y la ciencia fueron un enfoque importante de la discusión. Las herramientas geoespaciales innovadoras utilizan tecnologías de aprendizaje automático para derivar la inteligencia estratégica de los datos satelitales mediante el monitoreo de forma precisa de sectores que van del financiero, agrícola, y uso de tierra, hasta el manejo de desastres, aceite, gas y transportación. Estas también ofrecen nuevas oportunidades para rápidamente mapear y predecir las actividades económicas de los países en niveles micros y macros. El consenso fue que esta demanda de crecimiento requiere el fortalecimiento de las plataformas de distribución de datos y la construcción de un sistema de explotación de datos con base en tecnologías de comunicación e información avanzadas.

La IA también está permeando en la ciencia, la cual se está volviendo informática. La ciencia tradicional primero construye un modelo hipotético con base en la inteligencia humana y después evalúa el modelo con datos. En contraste, la ciencia informática utiliza "datos como el modelo" y reemplaza el entendimiento científico con la exploración científica. Los científicos de IA mencionaron que los sistemas de IA pueden detectar patrones y hacer descubrimientos en datos que los humanos no pueden detectar, así como explorar áreas de hipótesis que el conocimiento humano no puede imaginar. Los científicos en robótica realizan y optimizan los experimentos de alta precisión de una manera documentada reproducible. Los científicos humanos necesitan conceptualizar los problemas y proporcionar una retroalimentación para los algoritmos, pero el consenso fue que las instituciones de investigación, particularmente en los campos de la ciencia biomédica y ciencias de la vida, requerirán sistemas de IA capaces de mantener la competitividad.

\section{Es necesario enfrentar las amenazas a la privacidad individual y a los principios democráticos}

El crecimiento exponencial de la IA, y el consumo y análisis correspondientes de macrodatos, ha resaltado la necesidad de nuevas políticas y normas para proteger datos individuales y salvaguardar las instituciones democráticas, de acuerdo con los participantes. Recientes controversias en torno al papel de las plataformas de redes sociales en el uso indebido de datos personales y las denuncias de interferencia en los procesos democráticos ilustran los crecientes desafíos a los marcos de privacidad existentes. Los participantes discutieron el papel del nuevo Reglamento General de Protección de Datos (RGPD) de la Unión Europea como un medio para el fortalecimiento de la protección de datos en Europa $\mathrm{y}$ el endurecimiento de las penas por su uso indebido. Una propuesta fue el uso de equipos multidisciplinarios como un medio para incorporar la privacidad a las soluciones IA y para realizar evaluaciones del impacto de la privacidad para equilibrar la privacidad en relación con la funcionalidad y flexibilidad de la tecnología. 


\section{Un llamado a la justicia y a la rendición de cuentas}

Una conclusión clave de la conferencia fue un llamado a la transparencia en la toma de decisiones de la IA para garantizar justicia y la rendición de cuentas. Esto fue particularmente crítico para las decisiones impulsadas por la IA que tienen un impacto en las vidas de las personas. Un participante mencionó que la transparencia en la IA, a menudo referida como "explicabilidad", debe de permitir a las personas comprender cómo opera un sistema de IA y la cadena de razonamiento que lleva a una decisión. Más que la apertura de la "caja negra" de algoritmos, cosa que requeriría un nivel de comprensión técnica superior al de la mayoría de las personas, la explicabilidad ayudaría a los usuarios a comprender la forma en que se desarrollan, preparan e implementan los sistemas de IA.

Los participantes también enfatizaron la necesidad de transparencia y rendición de cuentas en las aplicaciones IA de alto nivel en justicia penal, vehículos autónomos, finanzas personales y atención médica. Por ejemplo, las autoridades y el público necesitarían comprender el proceso de toma de decisiones para resolver un caso en que un vehículo autónomo que enfrenta un accidente elige golpear a un ciclista o lastimar a su pasajero. Otro ejemplo mencionado fue la necesidad de explicar cómo se utiliza la IA para tomar la decisión si se debe preseleccionar o contratar a un solicitante de trabajo específico.

Cuestiones similares surgieron alrededor del impacto de los sistemas autónomos y autoaprendizaje con respecto a las normas en materia de responsabilidad y seguridad para productos de consumo. Los presentadores resaltaron la necesidad de hacer un replanteamiento más amplio sobre cómo deslindar responsabilidades y hacer cumplir las normas de seguridad para fabricantes y usuarios. Se citó el ejemplo de los electrodomésticos como una necesidad de desarrollo de las normas. Muchos aparatos cada vez son más autónomos, pero las normas de seguridad existentes se centran en el hardware más que en el software. Un representante comercial observó que los beneficios de seguridad de los productos de IA se deben de considerar junto con los riesgos, y que las normas de seguridad $\mathrm{y}$ de responsabilidad financiera deben coincidir con aquellas de los productos tradicionales.

Minimizar o eliminar el sesgo a medida que la IA tiene cada vez más injerencia en la toma de decisiones tradicionalmente controlada por personas, también estuvo en el radar. Cuando mencionaron numerosos ejemplos del sesgo informático, algunos participantes defendieron el concepto de "proporcionalidad", el cual requeriría una mayor transparencia para los sistemas que afectan las vidas humanas.

Se habló sobre la inteligencia artificial general (AGI, por sus siglas en inglés), que generalmente se ha definido como máquinas que igualan o superan el rendimiento humano en un rango completo de tareas cognitivas. La incertidumbre en torno a la viabilidad y los tiempos de la AGI ha dificultado analizar la temporalidad de las políticas, pero fue evidente que es un área con implicaciones que ameritan ser consideradas.

Los sistemas de IA se implementan tan ampliamente, y los cambios se presentan con tal velocidad, que algunos participantes sugirieron que era urgente considerar directrices nacionales y transnacionales que garanticen la interoperabilidad, que protejan los derechos humanos fundamentales, que reduzcan la desigualdad y que promuevan el bien común. Aunque reconocieron la dificultad para predecir el impacto de los sistemas de IA, participantes que representaban a todos los sectores coincidieron en que es necesario un amplio debate para prepararse para afrontar los efectos económicos y sociales.

\section{Es necesaria la articulación de los principios comunes para la IA en la sociedad}

Durante los dos días de la conferencia surgieron temas comunes de los diversos conjuntos de directrices propuestas y se discutieron las mejores prácticas. Entre los marcos de trabajo 
que ayudaron a alimentar la discusión se encontraron los principios de Diseño Alineados Éticamente y las normas que el Instituto de Ingenieros Eléctricos y Electrónicos están desarrollando a través de su "Global Initiative for Ethical Considerations in the Design of Autonomous Systems" (Iniciativa Global de Consideraciones Éticas para el Diseño de Sistemas Autónomos), los principios de Asilomar del Instituto Future of Life; los lineamientos sobre $\underline{\mathrm{I}+\mathrm{D} \text { de IA desarrollados a través de Ministerio de Asuntos Internos y Comunicación de Japón }}$ para investigadores y desarrolladores de sistemas de IA; la "Asociación sobre Inteligencia Artificial para el Beneficio de la Gente y Sociedad", que planea desarrollar principios de alto nivel así como lineamientos para ayudar a los investigadores y desarrolladores de IA; los Principios de la Unión Global UNI; los principios de Microsoft para la Asociación del Futuro; los Principios a través de la Asociación para Equipo Informático (ACM, por sus siglas en inglés) y la Iniciativa IA y los Principios de Robótica del Reino Unido.

Las discusiones resaltaron la oportunidad para que la OCDE parta de los principios y conocimientos existentes junto con sus socios para identificar los principios clave que impulsarán las políticas públicas y la cooperación internacional en materia de IA. La OCDE es vista como un foro sólido para el desarrollo de directrices internacionales sustentada en su enfoque en la evidencia y medición y en la participación efectiva de múltiples partes interesadas e interlocutores sociales en su trabajo. Este marco promovería la implementación de la investigación y aplicaciones de IA que refleje la necesidad de privacidad, protección, seguridad, autonomía y autodeterminación de la sociedad. El marco clarificaría objetivos y valores de alto nivel que ayuden a guiar el rápido desarrollo de la IA y a crear el fundamento normativo de los elementos clave para una transición exitosa a la IA. Se hizo hincapié en que los principios y reglas deben ser suficientemente flexibles, no deben frenar la innovación y deben involucrar a todas las partes interesadas. Diversos participantes insistieron en la urgencia de crear un marco de políticas públicas internacionales para ayudar a moldear el futuro de la IA y sus implicaciones, debido al acelerado desarrollo de la IA.

También se destacó el trabajo más amplio de la OCDE sobre un marco de políticas integrado para ayudar a los gobiernos a llevar la transformación digital a través de dominios de políticas (el proyecto "Going Digital") y la IA se consideró como una manifestación importante de la transformación digital con un impacto profundo en todas las sociedades - incluyendo en la productividad, empleo, modelos comerciales o servicio público y que requiere políticas públicas coherentes. Se observó el trabajo en curso y relacionado de la OCDE sobre el Acceso mejorado a datos: informes analíticos, una agenda de medición y posiblemente lineamientos, apuntan a equilibrar el acceso a los datos para beneficiar a la sociedad con principios básicos de privacidad. También hubo consenso sobre la necesidad de medir la difusión de los sistemas de IA más ampliamente que el PIB con base en conceptos como el Índice para una Vida Mejor de la OCDE. 


\section{Resumen detallado}

\section{SESIÓN DE BIENVENIDA}

Wonki Min, Presidente del Comité sobre Política en Economía Digital (CDEP, por sus siglas en inglés) de la OCDE, Corea, presentó la conferencia y agradeció al Ministerio de Asuntos Internos y Comunicación (MIC) de Japón por el respaldo brindado al trabajo de la OCDE sobre la IA y a la conferencia.

Garry Kasparov, Ex campeón Mundial de Ajedrez y autor de "Deep Thinking" (Pensamiento profundo) (a través de video) resaltó la puntualidad de la OCDE para abordar las políticas sobre máquinas inteligentes. Comparó el progreso de la humanidad con el trabajo del ser humano que más tarde fuera usurpado por los animales de granja, la manufactura y los cálculos, a lo que hoy son trabajos de cuello blanco. Cuando dijo que la tecnología desestabiliza las industrias antes de crear nuevos empleo y oportunidades, recordó que fue uno de los primeros trabajadores intelectuales cuyo trabajo se vio amenazado por la IA cuando perdió un juego de ajedrez contra la supercomputadora de IBM Deep Blue en 1998.

Señaló que cuando los seres humanos construyeron Deep Blue, usarían las máquinas inteligentes como una herramienta para mejorar las capacidades del ser humano. Añadió que las poderosas máquinas autónomas deben reflejar la moralidad humana y que la riqueza, productividad y seguridad generadas por la IA deben ser compartidas con el resto de la sociedad. Advirtió que mientras la IA fortalece a los seres humanos, no cambia su naturaleza; podrán utilizar la IA para el bien (educación, comunicación, comercio), o para el mal (propaganda política o terrorismo). Aconsejó a los participantes de la conferencia no tener miedo y que no intenten frenar la IA sino lo contrario, que sigan creando nuevas tareas e instrucciones no rutinarias que requieran únicamente la creatividad del ser humano.

Andrew Wyckoff, Director de Ciencia, Tecnología e Innovación de la OCDE, presentó el proyecto multidisciplinario "Going Digital: Making the Transformation Work for Growth and Well-being" (Hacia la digitalización: Hacer que la transformación funcione para el crecimiento y el bienestar) que involucra a 14 comunidades de políticas de la OCDE - desde hacendarias a comercio y hasta el transporte, y múltiples grupos de personas interesadas, comercio, sociedad civil, trabajo organizado y la comunidad técnica- para identificar conjuntamente las oportunidades y tratar los desafíos que las economías y sociedades enfrentan en un mundo cada día más digital y basado en datos. Describió la IA - con sus vínculos combinatorios al Internet de las Cosas (IoT), "big data" y aprendizaje automático - como una importante manifestación de la transformación digital. Mencionó que la IA afecta a la productividad, el empleo, los modelos comerciales y las relaciones humanas, recalcando la promesa notable de la IA que discierne los patrones complejos, detecta las irregularidades y ayuda a asignar los recursos de forma eficiente, lo que desencadena las innovaciones científicas y comerciales.

Como advertencia contra el exceso de promesas, pero también contra la propagación de miedo, siente que el desarrollo de la IA estuvo en un punto crítico y consideró el evento como un hecho memorable para discutir los marcos políticos e institucionales, así como los valores que deben guiar al uso y diseño de la IA. La rapidez del desarrollo de la IA hace esto urgente y significa que el sector privado y los tecnólogos tienen un papel que jugar vital. Las implicaciones de la IA están tan extendidas que la conversación debe ser inclusiva y global. 
Masahiko Tominaga, Viceministro para la Coordinación de Políticas, Ministerio de Asuntos Internos y Comunicación (MIC), Japón, habló sobre la visión de Japón en la cual la IA conecta los mundos digitales y físicos para los humanos e impulsa el desarrollo económico y la transformación social, lo que genera sabiduría que enriquece la vida de las personas y beneficia a la sociedad en general. Destacó los desafíos de la IA: seguridad, ciberseguridad, privacidad y ética. En concordancia con la estrategia de tecnología de IA de Japón y con la dirección de la industrialización presentadas en marzo de 2018, la investigación a través del Ministerio de Asuntos Internos y Comunicación (MIC) tiene como objetivo construir la IA de macrodatos sociales a partir del entendimiento de los mecanismos de la actividad cerebral.

Además, después de la Reunión de los Ministros de TIC del G7 celebrada en Japón en abril de 2016, el MIC convocó la "Conferencia hacia la Sociedad de Redes IA", un grupo de expertos multidisciplinarios para investigar los asuntos sociales, económicos, éticos y legales relacionados con la IA. En julio de 2017, el grupo elaboró el borrador de Directrices de I+D de IA. El Viceministro ofreció el apoyo de Japón y estas directrices para ayudar a avanzar las discusiones sobre la IA a nivel internacional, incluyendo en la OCDE. Recordó que la Reunión de Ministros de TIC e Industria del G7 en Turín, Italia en septiembre de 2017, compartió una visión de la IA "centrada en el ser humano" y pidió a la OCDE respaldar la cooperación y el diálogo de múltiples personas interesadas sobre la IA.

\section{SESIÓN 1: EL ESTADO DE LA INVESTIGACIÓN DE LA IA}

Kenneth Cukier, Editor Sénior, The Economist, Reino Unido, comparó la época dorada actual de la IA con el periodo vivido hace 20-25 años con la World Wide Web (Red Informática Mundial) y abrió la sesión para discutir las capacidades de la IA y el estado de la situación hoy y mañana.

Francesca Rossi, Científica Investigadora, IBM Watson y Profesora de Ciencias Informáticas, Universidad de Padua, Italia (Human-AI collaboration: technical and ethical challenges) (Colaboración entre humanos - IA; desafios éticos y técnicos) explicó que IBM se centra en IA que aumenta la inteligencia humana y que posibilita la toma de mejores decisiones. Subrayó los desafíos pendientes que se enfrentan para permitir la comunicación efectiva ser humano / máquina; el soporte proactivo de decisiones mediante máquinas a humanos y el mejoramiento de las máquinas con el paso del tiempo a través de las interacciones y con menos datos. También señaló los desafíos éticos: alineación de valores sin un conjunto universal de valores; confianza mutua y transparencia de los sistemas de IA y del manejo de datos; evitando sesgos, y desarrollando habilidades de la fuerza de trabajo; así como el involucramiento de todas las partes interesadas.

Stuart Russell, Profesor de Ciencias Informáticas, Universidad de California, Berkeley, Estados Unidos de América (Human-compatible artificial intelligence) (Inteligencia artificial compatible con humanos) señaló que la IA ha progresado mucho más rápido de lo esperado. Afirmó que, cuando tenga más información y sentido de anticipación, la IA tomará mejores decisiones que los seres humanos y es probable que reemplace el trabajo humano. Dado que las nuevas ocupaciones, por ejemplo, los científicos de datos, no proporcionarán muchos puestos de trabajo, previó que los seres humanos se enfocarían en trabajos para mejorar la vida de los demás. Si bien hoy en día dichas ocupaciones con frecuencia son mal remuneradas, la creciente profesionalización y un mayor énfasis en la investigación llevarían a un valor añadido e ingresos mayores. Esto a su vez, sugiere la necesidad de cambios significativos en la educación y ciencia.

Explicó cómo evolucionar el diseño de los sistemas de IA desde la optimización de un objetivo dado hasta la "IA beneficiosa" para los humanos con base en las técnicas de la IA 
para aprender las preferencias humanas. Explicó por qué las limitaciones informáticas de los seres humanos, las preferencias inconsistentes y la antipatía dificultaron esta tarea. Sin embargo, se mostró optimista de que lo podríamos hacer bien siempre y cuando tengamos incentivos económicos sólidos y cantidades importantes de datos acerca de las elecciones del ser humano en el documento.

Rodolphe Gelin, Líder de Ingeniería de Software en Robótica, SoftBank Robotics, París (Robots, man's best friend) (Robots, los mejores amigos del hombre) mencionó que los robots ayudarían a los seres humanos más que reemplazarlos. Presentó el enfoque de Softbank para la robótica, el cual se centra en el mercado entre empresas y en el uso de robots en la educación como un complemento para los maestros, para proporcionar asistencia a adultos mayores y en el futuro como un compañero para la familia. Enfatizó que los propietarios de robots preferirían aquellos que les obedezcan más que robots éticos.

Osamu Sudoh, Profesor, Universidad de Tokio, Iniciativa Interfactultades en Estudios de Información, Japón (Towards AI network society — addressing social, economic, ethical and legal issues) (Hacia una sociedad de redes IA- abarcado los asuntos sociales, económicos, éticos y legales) presentó el "Artificial Intelligence Technology Strategy Council" (Consejo de Estrategia de Tecnología en Inteligencia Artificial) instituido por el gobierno japonés y su estrategia para la industrialización de la IA. Para 2020, Japón tiene como objetivo haber estandarizado e interconectado los datos públicos para activar los servicios públicos avanzados para la sociedad. Para 2025-2035, Japón conectará diversas IA para constituir ecosistemas que posibiliten a la sociedad. El Consejo de Ciencia, Tecnología e Innovación de Japón visión "Society 5.0" interconectará perfectamente los mundos físicos y cibernéticos.

Al recordar el trabajo realizado por el MIC japonés, recordó: i) interoperabilidad - los sistemas de IA actualmente son diferentes entre una compañía y la otra, sin embargo, será necesaria la comunicación para crear valores, por ejemplo, los vehículos autónomos de diferentes fabricantes deben comunicarse entre ellos, lo que crearía la necesidad de una estandarización de los datos; ii) la interacción entre seres humanos - IA en la cual las personas coevolucionen con la IA y no teman a la superinteligencia, de acuerdo con la propuesta de Japón en la Reunión de Ministros de TIC del G7 en Takamatsu para desarrollar directrices de I+D de IA; y iii) ajustes para abordar el impacto social de la IA, en particular, la revisión de los sistemas de seguridad social más sostenibles para una mundo con robots e IA - por ejemplo, la experimentación con un ingreso básico en Finlandia y sistemas de educación que evolucionen para que las personas puedan aprender cómo utilizar la IA como una herramienta para afrontar los desafíos globales.

Philipp Slusallek, Director Científico en DFKI, Alemania, se centró en las formas de garantizar que los sistemas de IA interactúen de forma segura y confiable con el muy complejo mundo real (Artificial intelligence and digital reality: Do we need a "CERN for AI"?). (Inteligencia artificial y realidad digital: ¿Necesitamos un “CERN para la IA”?). Definió la IA como "sistemas que son capaces de percibir, aprender, comunicar, razonar, planear y simular en un mundo virtual y actuar en el mundo real", es decir, la IA comprende de forma simultánea el mundo real mediante modelos de aprendizaje o las "reglas del juego". Explicó que el aprendizaje automático es el mejor método para que dichos sistemas adapten y aprendan acerca de las interacciones complejas con el mundo real. No obstante, normalmente se requiere entradas de grandes datos para la capacitación y no permite la validación formal de los resultados. Por ejemplo, debido a que los sistemas no pueden ser entrenados y evaluados en el mundo real, no existe garantía de que un carro autónomo reaccionará correctamente si se enfrenta con el riesgo de golpear a un niño. 
Propuso la idea de una "realidad digital", un entorno simulado que replique las características importantes del mundo real para: $i$ ) generar datos de entrada para preparar a los sistemas de IA en situaciones complejas mediante el modelado del mundo real con el fin de generar datos sintéticos; ii) evaluar por comparación mediante la reproducción y estandarización de los escenarios de prueba; iii) validar el rendimiento y recalibrar los datos sintéticos contra los datos reales, para identificar y adaptar modelos incompletos y configurar las pruebas (como una "prueba de manejo para licencia" para los vehículos autónomos); y iv) explorar el proceso de toma de decisiones del sistema y los resultados potenciales de las decisiones alternativas.

Mediante este tipo de simulación, AlphaGo Zero fue capaz de aprender a jugar Go de forma sobrehumana sin datos, al simplemente jugar Go contra sí mismo. Pero dado que las "reglas del juego" de la realidad son mucho más complejas que Go y que no están articuladas, serían necesarios modelos parciales basados en datos del mundo real para crear una realidad digital. Por ejemplo, para la conducción de vehículos, se combinaron diferentes modelos, por ejemplo, de movimiento peatonal, ambientes de tráfico, etc., para describir escenarios, incluyendo escenarios críticos para los cuales no existen datos, como niños corriendo enfrente de un carro (diferentes tamaños de niños, ropa, direcciones, velocidades, condiciones del alumbrado, etc.). Las simulaciones generarían los datos del sensor sintético requerido (para cámaras, radar, detección de luz y distancia [lidar, por sus siglas en inglés], etc.) que un carro real observaría en la realidad en este tipo de situación.

El Sr. Slussalek lanzó un llamado para lograr enfoques comunes ante los desafíos y una plataforma y comunidad de investigación conjunta o "CERN para la IA" como un esfuerzo científico colaborativo para mejorar continuamente y comprender el mundo real; para proporcionar una plataforma transparente, abierta y flexible que respalde la investigación y facilite la transferencia / intercambio con la industria y para utilizar la plataforma para un amplio debate de las políticas y consecuencias de usar la IA.

El debate se centró en la transparencia o "explicabilidad". Los participantes enfatizaron la necesidad de contar con explicaciones y de un proceso de interrogación máquina-humano, particularmente en recomendaciones o decisiones de alta prioridad en áreas como la justicia penal, las finanzas personales y la atención de la salud. También señalaron que, en muchos casos, existe una interrelación entre la explicabilidad y el rendimiento/exactitud. Los expertos en IA explicaron los distintos enfoques técnicos que se pueden adoptar, ya sea incorporando explicaciones en la capacitación o el sistema como tal, o tratando los resultados como un problema científico y obteniendo algunas explicaciones de forma indirecta. Mencionaron que el nivel de incertidumbre del sistema de IA se debe comunicar a los planificadores de decisiones humanos, quienes deben aceptarlo, aunque no sería preciso. Podría realizarse un análisis de sensibilidad de las variables críticas en algunos casos con el fin de explicar por qué un curso de acción es óptimo, con árboles de decisiones y explicaciones multicapa. El índice de error permisible es probablemente para variar dependiendo de la aplicación. Por ejemplo, el índice de éxitos de $87 \%$ del sistema japonés Voicetra podría ser aceptable para la traducción, pero no para la conducción autónoma o los exámenes médicos.

Los ponentes también destacaron la importancia de no crear máquinas que puedan elegir matar a seres humanos de forma autónoma y la necesidad de que alguien se haga responsable de las acciones del robot. También mencionaron que la IA en su estado actual no es revolucionaria, pero podría llegar a serlo cuando los sistemas de IA individuales puedan entenderse entre ellos, puedan trabajar juntos sin que lo seres humanos los enseñen y puedan actuar con "sentido común". 


\section{SESIÓN 2: ESTUDIOS DE CASOS Y APLICACIONES DE LA IA}

Andrew Wyckoff, Director de Ciencia, Tecnología e Innovación de la OCDE, presentó la sesión sobre las aplicaciones que se dan a la IA en la vida real para tomar mejores decisiones, reducir los costos y mejorar la productividad en una variedad de dominios en las aplicaciones en la vida real en el sector de salud, transporte, seguridad, así como áreas inesperadas como las artes y cultura y servicios.

Valerio Dilda, Socio, McKinsey \& Company, París, presentó las conclusiones de un informe reciente de McKinsey (AI: perspectives and opportunities) (IA: perspectivas y oportunidades). En áreas como el reconocimiento de imagen, el rendimiento de IA ha llevado a cabo grandes procesos recientemente para ahora superar a los seres humanos. Desde 2010, la exactitud del reconocimiento de imagen creció de menos de $70 \%$ a $96 \%$ mientras que el nivel de exactitud del rendimiento humano se encuentra en 95\%. Citó a Andrew Ng para mencionar que la "IA es la nueva electricidad" y ya tiene un impacto comercial importante. Por ejemplo, Netflix atribuye 1 mil millones de dólares de ingresos al cambio de proveedor gracias a la IA y Amazon atribuye a la IA con una reducción del $75 \%$ en el tiempo entre que se da clic para hacer un pedido hasta el envío. La IA automatiza las tareas más que los trabajos. $40 \%$ de las tareas pueden ser reemplazadas, pero menos del $10 \%$ de los trabajos se reemplazarán.

Mckinsey encontró que la adopción a escala era limitada. Las empresas que utilizan la IA tienden a hacerlo en su negocio central para impulsar los ingresos y para optimizar los costos mediante la identificación de los asuntos con los que la IA podrá ayudar. Por sector, las industrias digitalmente maduras que cuentan con datos que pueden aprovechar - finanzas, tecnología \& telecomunicaciones y automotriz- lideran en términos de inversiones de la IA actuales y futuras. Las empresas que adoptan la IA de forma anticipada o temprana también tienden a ser empresas más grandes. McKinsey estima que la adopción de la IA en comercios minoristas podrá incrementar las ventas un $30 \%$, optimizar el tiempo de producción un 30\% durante la fabricación, reducir los costos de electricidad en un $10 \%$ y generar ahorros potenciales de más de $10 \%$ en servicios de la salud.

Reinhard Stolle, Departamento de Inteligencia Artificial en BMW AG, Múnich $(\underline{A I}$ as a driver of the automotive industry) (La IA como conductor de la industria automotriz) describió el desarrollo de las aplicaciones de conducción autónoma de BMW. Describió cinco niveles de automatización para la conducción en los que los niveles 0 al 2 son la tecnología de punta, el nivel 3 involucra la conducción autónoma en autopistas mediante el uso de humanos como respaldo y los niveles 4 y 5 no presentan intervención humana. La IA, el aprendizaje automático y el big data están a bordo de los vehículos a través de sensores, comprensión de escena, planeación y ejecución de las acciones, así como fuera del vehículo con bucle de datos de recolección, evolución a través de la capacitación y simulaciones.

Max Yuan, fundador y presidente, Xiaoi Robot Technology, Shanghái (AI empowers government and enterprises) (La IA empodera a gobiernos y empresas) ofreció un panorama general de las aplicaciones conversacionales de la IA de Xiaoi que procesan 3 millones de conversaciones diariamente en la República Popular de China (en lo sucesivo "China"), lo que redujo el número de llamadas por 2 millones mensualmente y disminuyó los costos cerca de 14 millones de dólares. Resaltó las aplicaciones de la tecnología conversacional de la IA en: $i$ ) atención al cliente inteligente (IA + los canales en línea), incluyendo la capacitación y la comercialización; ii) ciudades inteligentes (cerebro de la ciudad inteligente) y servicios públicos inteligentes (ejemplo, el sistema de servicio inteligente de flujo automático para la ciudad de Guiyang); iii) aplicaciones robóticas inteligentes que combinan la robótica y la IA; iv) dispositivos inteligentes con un sistema de operación máquina-mente utilizados 
en casas inteligentes, vehículos inteligentes, accesorios inteligentes (wearables), robots inteligentes; $\mathrm{y} v$ ) oficinas inteligentes.

Lynette Webb, Gerente sénior, Estrategia de Política Europea, Google, Londres (Machine learning in action) (Aprendizaje automático en acción) enfatizó que el aprendizaje automático no es magia sino matemáticas, coincidencia de patrones y probabilidad. Explicó que el aprendizaje automático es un componente cada vez más clave de los productos de Google. Sin embargo, requiere datos curados y precisos; suficiente potencia de la computadora y herramientas para la capacitación y personal para la configuración y evaluación de los resultados. Google utiliza la traslación de la máquina estadística para traducir más de mil millones de palabras diariamente, el reconocimiento de voz que está alcanzando niveles de exactitud cercanos a los humanos; y usa el reconocimiento de imagen para categorizar de forma automática objetos y conceptos. Brindó ejemplos de aplicaciones. AIRBUS utiliza las herramientas de IA para automatizar la detección y corrección de los bancos de imágenes satelitales. Un servicio de subasta de vehículos japonés utiliza la IA para clasificar de forma automática fotografías cargadas por distribuidores de autos usados. Rolls Roys detecta, clasifica y rastrea objetos que los barcos encuentran en el mar. Connecterra rastrea el comportamiento del ganado a través de sensores y utiliza el aprendizaje automático para advertir a los granjeros cuando una vaca pudiera estar enferma.

Resaltó la importancia de la apertura y de normas comunes para el éxito del aprendizaje automático. Explicó que Google comparte conjuntos de datos de capacitación, herramientas y material de capacitación especializados. También presentó la reciente iniciativa Gente + Investigación de la IA (PAIR, por sus siglas en inglés) en Google y añadió que Google participa en el Laboratorio de Ética Digital en el Instituto de Internet de Oxford y en la asociación sobre la IA.

Durante el debate los participantes resaltaron:

- El posible impacto de la IA sobre los empleos y la probabilidad de que, como se mencionó en un informe reciente del Foro Internacional de Transporte (ITF, por sus siglas en inglés) sobre camiones autónomos, los niveles 4 y 5 de la automatización de vehículos podría reducir tanto los costos de transporte en camión, alrededor de 30\%, que los que no adoptan esta opción serían expulsados rápidamente del negocio y los pequeños jugadores tendrían que consolidarse o desaparecer.

- El papel de la IA en el mejoramiento de los servicios públicos y para mejorar la eficiencia y la exactitud de las decisiones de políticas públicas.

- Las respectivas funciones del gobierno, la academia y los actores privados para facilitar y mantener las tecnologías de IA y los datos en áreas públicas para impulsar la innovación:

- Mientras que el éxito viene con la inversión y la prueba y error, los datos disponibles muestran que las firmas que invierten en la IA y obtienen ganancias de ella, son empresas grandes.

- En este contexto, cómo permitirle a las PyME adoptar y beneficiarse de la IA, por ejemplo, a través de la capacitación y ayuda a las PyME para que realicen las inversiones requeridas en tecnología y datos.

- El papel de los planeadores de políticas públicas para enfocarse en sectores de integración vertical seleccionados que podrían beneficiarse de la IA. Por ejemplo, en el sector agrícola francés, las políticas para impulsar la inversión en aplicaciones de la IA especificas podría beneficiar a todos los jugadores, mientras que los jugadores individuales podrían no realizar estas inversiones por sí solos en un sector fragmentado con muchas PyME. 
- La gobernanza de la toma de decisiones mediante el uso de la inteligencia asistida para informar y respaldar decisiones más rápidas y exactas por parte de los seres humanos.

- Ética por diseño y cómo construir la ética en los sistemas de IA requiere diálogo, ya que las reglas por las que se guían los humanos y, por ejemplo, conductores humanos, no están escritas y los automóviles necesitarán romper algunas reglas escritas.

\section{SESIÓN 3: ACERCAMIENTO A LA IA EN APLICACIONES ESPACIALES}

Claire Jolly, Jefa del Foro Espacial de la OCDE, abrió la sesión organizada por el Foro Espacial de la OCDE que proporcionó una descripción general de herramientas geoespaciales innovadoras que emplean tecnologías de aprendizaje automático para derivar inteligencia estratégica a partir de datos satelitales y para realizar predicciones.

Tugdual Ceillier, Científico de datos en Jefe, EarthCube, Toulouse (Artificial intelligence and remote sensing: new capabilities to monitor infrastructure) (Inteligencia artificial y percepción remota: nuevas capacidades para monitorear la infraestructura) explicó la forma en que Earthcube combina imágenes satelitales e IA para investigar amenazas a oleoductos. Las amenazas al sistema provienen de la actividad humana cerca de los oleoductos, incluyendo, por ejemplo, deforestación, vehículos en movimiento, trabajos de nivelación y construcción de nuevos sitios y de carreteras. La IA ayuda a detectar las amenazas mediante el reconocimiento de patrones en las imágenes satelitales.

Bryan Yates, Director de ventas - región de Europa, Oriente Medio y África, Orbital Insight, Mountain View, California (New geoanalytics: tracking economies from space) (Nueva geoanalítica: rastreo de economías desde el espacio), explicó cómo Orbital Insight aplica los algoritmos de aprendizaje automático/profundo y la visión artificial para procesar, clasificar y analizar las imágenes obtenidas por vehículos aéreos o aéreos no tripulados (VANT) para contar, clasificar y detectar los cambios entre dominios, por ejemplo, los niveles de cisternas de combustible en azoteas, los niveles de agua, el rendimiento y la salud de los cultivos, clasificación de terrenos y edificios, así como redes de caminos, conteo de automóviles y camiones, monitoreo de actividades mineras y existencia de mercancías. Las imágenes satelitales son analizadas mediante aprendizaje automático y se combinan con los datos financieros y de fabricación para generar percepciones que puedan incrementar los ingresos y ahorrar costos.

Thanh-Long Huynh, Director General, Quantcube Technology, París (Big data analytics for strategic intelligence) (Análisis de big data para la inteligencia estratégica) mencionó que Quantcube analiza fuentes alternativas de información para realizar inteligencia estratégica a corto, mediano y largo plazos. Las fuentes empleadas incluyen datos satelitales, redes sociales, redes profesionales, minoristas en línea, blogs, comercio electrónico, datos meteorológicos y datos de tráfico terrestre, marino y aéreo. Los datos recolectados van de imágenes hasta texto y se utilizan para realizar predicciones sobre las tendencias energéticas (por ejemplo, con base en las noticias de la reunión de la OPEC), del sector manufactura (por ejemplo, con base en las imágenes de nuevas fábricas y nueva infraestructura, o recursos (por ejemplo, con base en la geolocalización de barcos que transportan hierro, minerales y energía).

Bahaa Alhaddad, Desarrollo de Negocios Espaciales, Starlab Space, Harwell Oxford, Reino Unido (Neurosciences and space data: a new big bang) (Neurociencia y datos espaciales: un nuevo big bang) mencionó que Starlab utiliza el aprendizaje automático para analizar datos geoespaciales para la gestión verde urbana con el fin de monitorear la salud de los árboles dentro de las ciudades y para desarrollar "ciudades más felices" en combinación con monitoreo neurocientífico de la actividad cerebral en distintos entornos 
urbanos (presencia de áreas verdes, parques, museos, sitios históricos, etc.). La localización de áreas verdes en mapas satelitales ayuda a identificar "áreas felices" en aglomeraciones urbanas, que a su vez se utilizan para sugerir itinerarios o para proporcionar información sobre la calidad de los vecindarios urbanos.

Alexander Cooke, Consejero, Departamento de Industria, Innovación y Ciencia, Australia (Digital Earth Australia) presentó el proyecto Digital Earth Australia (DEA) del gobierno australiano, para incrementar la eficacia y eficiencia de las políticas y programas públicos que requieren información espacial oportuna y precisa sobre la salud y la productividad del panorama australiano. El DEA utiliza datos de Sentinel 2, los cuales son recopilados y analizados mediante técnicas de aprendizaje automático para modelar los planes de cuencas y monitorear y crear modelos de riego, oceánicos y de costas y para proporcionar respuestas ecológicas dinámicas.

Christophe Roeland, Responsable de Políticas, Dirección General para el Mercado Interno, Industria, Emprendimiento y PyME, Comisión Europea, Bruselas (EC perspectives on the earth observation revolution) (Perspectivas de la CE sobre la revolución de la observación de la tierra) ofreció un panorama general sobre Copernicus, el Programa Europeo para la constitución de un grupo europeo para la Observación de la Tierra. Creado a finales de la década de 1990, recopila y procesa datos satelitales de los satélites Sentinel, así como datos de sensores de compañías privadas y socios internacionales. El programa ofrece servicios basados en los datos de áreas tan variadas como la atmósfera, entorno marino, terrestre, cambio climático, gestión de emergencias y de seguridad. Con excepción del área de seguridad, los ciudadanos, las autoridades, los investigadores y las empresas podrán utilizar los datos satelitales y los componentes de servicio de forma libre y gratuita. Resaltó los desafíos relacionados con el enorme volumen de datos que genera el programa Copernicus y describió el proyecto de la Comisión Europea para desarrollar un entorno basado en la nube de datos - el Servicio de Acceso a Datos e Información (DIAS, por sus siglas en inglés) - para brindar a los usuarios acceso a datos y a la capacidad de procesamiento de datos en la nube donde estos podrán ejecutar sus algoritmos.

\section{Estos son algunos aportes específicamente relacionados con el espacio:}

En muchas partes del mundo, las compañías emprendedoras están aprovechando el aprendizaje automático y un "aluvión" de datos satelitales para crear productos y servicios innovadores. Se resaltó el papel clave de las políticas públicas, en particular: i) la importancia de políticas de datos abiertos a los datos satelitales con financiación pública, para permitir a las PyME crear productos con valor añadido así como el aprovechamiento de los servicios, por ejemplo, la flota de satélites Copernicus desarrollada por la Agencia Espacial Europea fundada por los Unión Europea o por Landsat en los Estados Unidos de América; ii) la necesidad de la interoperabilidad y normas especialmente para el archivado de datos y la consulta de los mismos; y iii) la necesidad de habilidades futuras en vista de la competencia por ingenieros y científicos en aprendizaje automático.

\section{SESIÓN 4: MEJORAR LOS DESCUBRIMIENTOS - EL PAPEL DE LA IA EN LA CIENCIA}

Dominique Guellec, Jefe de la División de Políticas en Ciencia y Tecnología de la OCDE, presentó la sesión sobre la IA en las ciencias, cuyo objetivo fue explorar oportunidades y desafíos de la aplicación de la IA en la ciencia. Los puntos de debate incluyeron los usos actuales y emergentes de la IA y el aprendizaje automático en la ciencia; las limitaciones del uso de la IA en la ciencia; las oportunidades que la IA ofrece para incrementar la productividad en la investigación, los desafíos planteados para los investigadores y 
asuntos planteados en torno a la ciencia educativa, patrocinadores para la investigación y planeadores de políticas.

Stephen Roberts, Profesor de Aprendizaje Automático en Ingeniería Informática, Universidad de Oxford, Reino Unido (21st century science: the age of intelligent algorithms) (Ciencia en el siglo 21; la era de los algoritmos inteligentes) resaltó las fuerzas motrices de los avances en IA, el creciente volumen de datos generados por la gente, el progreso en los algoritmos de aprendizaje automático y el crecimiento exponencial de capacidades informáticas asequibles. Enfatizó el poco visible, pero muy importante, papel de la IA para la selección de grandes volúmenes de datos. Recalcó el nuevo paradigma científico impulsado por la ciencia de datos en el cual la adquisición de datos es la prioridad y en el que los científicos amplían los descubrimientos realizados por la ciencia algorítmica en experimentos grandes.

Distinguió las aplicaciones principales de la IA y el aprendizaje automático en la ciencia de la siguiente forma: $i$ ) Detección y descubrimiento; por ejemplo, el análisis de datos a gran escala hizo posible detectar planetas en el proyecto del telescopio espacial Kepler; ii) Derivación de principios de la observación de datos: por ejemplo, la ley de la dinámica de Newton podría ser deducida a partir de la observación de datos de objetos caídos; iii) Human-in-the-loop, es decir, la combinación de la sabiduría y conocimientos humanos con algoritmos para crear un mecanismo de retroalimentación eficaz para resolver los desafíos globales; y $i v$ ) experimentos inteligentes, por medio de los cuales la IA optimiza el diseño de experimentos a gran escala, como el diseño de nuevos materiales, medicamentos o tratamientos. Concluyó que la era de la ciencia automatizada ha comenzado.

Hiroaki Kitano, Presidente y Director General de Sony Computer Science Laboratories, Japón (The Nobel Turing Challenge: creating the engine of scientific discovery) (Desafio de Turing: creación de la ingeniería del descubrimiento científico) presentó el "Nobel Turing Challenge" cuyo objetivo consiste en estimular el desarrollo de Sistemas de IA que puedan realizar descubrimientos científicos importantes merecedores de un Premio Nobel y que puedan ejecutar tareas científicas de forma autónoma, como elegir un tema y comunicarse con la comunidad, al igual que un investigador humano. El enfoque primario de este reto se encuentra en la ciencia biomédica, para el Premio Nobel de Fisiología o Medicina.

Mencionó que los descubrimientos científicos se ven limitados por la capacidad cognitiva del ser humano y por la dependencia en la intuición y serendipia de los investigadores. La IA podría ayudar a la ciencia a realizar búsquedas masivas y a verificar la totalidad del espacio de versiones al contar con cada vez más datos y potencia de cálculo informativo masiva. Identificó tres fortalezas de la IA para la investigación científica: i) detección de patrones que el ser humano no puede detectar, ii) realización de experimentos de alta calidad, y iii) exploración de hipótesis que los humanos no pueden imaginar. Hizo una demostración con música al estilo de los Beatles que había sido compuesta completamente por IA y se mostró optimista con respecto a que el conocimiento creado por IA podría hacer una diferencia cualitativa en la evolución de la civilización humana.

Ross King, Profesor de Inteligencia Artificial, Facultad de Ciencias Informáticas de la Universidad de Manchester, Reino Unido (The automation of science) (La automatización de la ciencia) identificó cómo los Sistemas de IA aumentan el número de científicos con razonamiento lógico perfecto, al aprender de vastas cantidades de datos y al leer millones de documentos científicos. Presentó los Científicos Robóticos que combinan los sistemas de IA y la automatización de laboratorio para crear experimentos, ejecutarlos físicamente, interpretar los resultados y repetir el ciclo de experimentos. Mencionó que los Científicos Robóticos pueden trabajar más duro, más rápido y más eficientemente, fueron 
más fáciles de reproducir (que los científicos humanos que deben ser capacitados desde cero) y ayudaron a mejorar el conocimiento y a compartir datos. Ilustró su ponencia con un video de científicos robóticos llamados "Adán" y "Eva". Describió el trabajo de estos robots en medicamentos contra enfermedades tropicales - encontraron que un compuesto llamado "Triclosán Reposicionado" comúnmente utilizado en dentífricos, es eficaz contra la malaria. Mencionó que, al igual que los equipos que combinan humanos y computadoras juegan mejor el ajedrez que cualquiera de los dos solos, los científicos humanos y robóticos podrían colaborar para mejorar la productividad de la ciencia para obtener beneficios sociales, por ejemplo, mayor seguridad en los alimentos y mejores medicamentos.

Jonathan McLoone, Director Técnico, Wolfram Research Europe (Preparing science for AI: rethinking education, research and publication) (Preparación de la ciencia para la IA: replanteamiento de la educación, investigación y publicación) describió como la IA y el pensamiento computacional requieren prácticas de replanteamiento en $i$ ) descubrimiento científico, ii) difusión de la ciencia, y iii) educación científica. Respecto al descubrimiento, resaltó que el pensamiento computacional es un proceso de exploración más que uno de entendimiento. Mientras que la ciencia tradicional primero construye un modelo hipotético con base en la inteligencia humana y después evalúa el modelo con datos, la ciencia computacional utiliza los datos como el modelo. Otro cambio es de una mentalidad de simplicidad hacia una mentalidad de complejidad: la ciencia tradicional tiene como objetivo eliminar el ruido para evaluar el modelo a través de la experimentación, mientras que el pensamiento computacional requiere tantos datos como sea posible, incluyendo el ruido que podría ayudar a señalar la solución.

La difusión científica tradicional y los procesos de publicación se basan en la revisión por pares, mientras que la reproducibilidad es crucial en el pensamiento computacional. La reproducibilidad requiere tener acceso al código del experimento de aprendizaje automático, así como a datos legibles por la máquina. Lanzó un llamado para que se implementen reformas diseñadas para estimular que los científicos proporcionen códigos y datos en las publicaciones científicas que faciliten la reproducibilidad.

Destacó la importancia de adaptar la educación para preparar a los estudiantes para el pensamiento computacional mediante: la adaptación de la educación en matemáticas para priorizar el trabajo conceptual en vez del cálculo escrito a mano (en las clases de matemáticas actuales la mayoría del tiempo se invierte en simples cálculos escritos a mano que son demasiado simples para los problemas científicos reales). Recomendó que los planeadores de políticas adapten el sistema educativo tradicional y la difusión científica con el fin de prepararse para el pensamiento computacional y los experimentos de aprendizaje automático en la ciencia.

En el debate los participantes plantearon asuntos que podrían requerir atención política:

- Los gobiernos controlan los activos de datos de salud pública que podrían aprovecharse con la IA para los descubrimientos científicos, no obstante, los participantes sintieron que las políticas actuales favorecen la privacidad sobre el progreso científico.

- Las empresas privadas son líderes en el desarrollo e investigación de la IA actuales, sin embargo, los gobiernos y la investigación pública juegan una función clave en el aprovechamiento de la IA con el fin de ayudar a resolver los desafíos globales.

- En el futuro cercano, las instituciones de investigación requerirán sistemas de IA capaces de permanecer competitivos, particularmente en la ciencia biomédica y ciencias de la vida.

- El descubrimiento científico impulsado por IA requiere inversión de capital a gran escala para preparar recursos ricos en datos, laboratorios automatizados e 
instalaciones informáticas a gran escala. Esto podría provocar la concentración del descubrimiento científico y plantea inquietudes acerca del monopolio excesivo del conocimiento científico.

\section{SESIÓN 5: EL PANORAMA DE LAS POLÍTICAS DE IA}

Anne Carblanc, Jefa de la División sobre Política de Economía Digital de la OCDE, presentó la sesión 5 , cuyo objetivo era brindar un resumen del panorama de las políticas de IA, cubriendo las iniciativas de los gobiernos, el sector privado, las comunidades de investigación, la sociedad civil y los sindicatos. Subrayó que fomentar el desarrollo beneficioso de la IA se ha convertido en una prioridad no solo a nivel nacional, por ejemplo, en Japón, China y Finlandia, sino también a nivel internacional, como en los niveles del G7 y la UE.

David Heiner, Asesor en Política Estratégica en Microsoft, representante de la Asociación para Inteligencia Artificial (Partnership on Artificial Intelligence) (Enabling the promise of artificial intelligence) (Hacer posible la promesa de la inteligencia artificial) mencionó que Microsoft y otras compañías de IA reconocen que es necesario abordar temas como la imparcialidad, la transparencia y la responsabilidad para que la gente pueda confiar en la IA. Afirmó que la IA sobresale en tareas específicas y puede razonar sobre grandes cantidades de datos, al convertir video, habla y sonidos en texto con reconocimiento de imagen. Pero extraer el significado de dicho texto es complicado y requiere personas con cualidades humanas como la empatía, el criterio y la imparcialidad. La IA puede permitirles a las personas interactuar con las computadoras de forma más natural con interfaces mejoradas y naturales y puede diseñarse para amplificar la ingenuidad humana.

Enfatizó que la IA no debería estar bajo el control de un número reducido de compañías estadounidenses y mencionó que Microsoft estaba poniendo gran parte de su tecnología de IA de reconocimiento de imágenes a disposición del público, mediante la creación de servicios para usuarios finales y exponiendo las interfaces de programación a los desarrolladores para que cualquiera pueda desarrollar aplicaciones nuevas. Presentó el marco de trabajo de Microsoft para amplificar la ingenuidad humana en beneficio de todos y señaló que la IA también podría ayudar a abordar cada problema, por ejemplo, los automóviles autónomos mejoran la confiabilidad y la seguridad; las computadoras podrían no tener los mismos sesgos que los humanos; los agentes de IA pueden ayudar a mejorar la seguridad y privacidad. Presentó la "Asociación sobre IA para el beneficio de las personas y la sociedad", la cual celebró su primera reunión en Berlín esa misma semana para tratar la imparcialidad, la transparencia y la responsabilidad y en ella se planeó desarrollar un alto nivel de principios y directrices para ayudar a los investigadores y desarrolladores de IA.

Nicolas Miailhe, Cofundador y Presidente, The Future Society; Científico Visitante Sénior, Harvard Kennedy School of Government (Harnessing the power of collective intelligence to govern the rise of AI: the case of "algorithmictransparency \& accountability") (Aprovechar el poder de la inteligencia colectiva para regir el crecimiento de la IA: el caso de la "trasparencia y responsabilidad algorítmica"), presentó el "Debate Cívico Global sobre la Gobernanza de la IA" que él dirige. Desde su punto de vista, los problemas de la IA son los problemas del big data, ya que la IA se alimenta de los cada vez mayores flujos y reservas de datos. En su opinión, una cuestión clave sería por lo tanto cómo monetizan los datos el sector privado y público y cómo comparten el valor con los consumidores. Consideró que el RGPD (Reglamento General de Protección de Datos) europeo es crucial para la portabilidad de datos. 
Miailhe abogó por un "entorno regulatorio controlado" para la IA que les permita a los actores jugar con los datos a escala lejos de las restricciones legales porque: $i$ ) la correlación algorítmica debilita la distinción entre los datos personales y los demás datos; los datos no personales podrían permitir que se vuelva a identificar a un individuo; ii) la IA debilita la distinción entre la experimentación y la utilización de la IA; iii) los países que buscan soberanía en el campo de la IA deben equilibrar las obligaciones en pugna de la privacidad y la controlabilidad, con flujos de datos libres que utilicen tanto actores privados como públicos. También señaló los objetivos que compiten de dignidad/privacidad contra el acceso a la tecnología.

Benedetta Arese Lucini (Italia) (G7 Italy: towards a human-centric AI) (Italia del G7: hacia una IA enfocada en los humanos), presentó el resultado de la Reunión Ministerial de TIC e Industria del G7 que se celebró en Turín en septiembre del 2017 bajo la presidencia italiana. La Declaración Ministerial de TIC e Industria del G7 fue el primer texto acordado a nivel internacional sobre la IA. Los países del G7 reconocieron los inmensos beneficios posibles de la IA, pero también su impacto incierto sobre la sociedad y la economía. Convinieron tomar un enfoque "centrado en los humanos" para la IA y: $i$ ) ganar entendimiento sobre el impacto cultural, ético, regulatorio y jurídico de la IA; ii) tomar en cuenta el resultado del diálogo entre las diversas partes interesadas durante la Reunión Ministerial para explorar tanto el impacto positivo como controversial de la IA, en particular en el crecimiento, la creación de empleos, la responsabilidad, la privacidad y la seguridad; iii) perseguir un enfoque de varias partes interesadas como una manera efectiva de abordar problemas de políticas y de asuntos regulatorios; y iv) trabajar hacia un entendimiento común sobre cómo beneficiarse del potencial completo de la IA para una sociedad equitativa, y enfatizando al mismo tiempo que las regulaciones no deben dificultar el desarrollo de la tecnología y la industria.

Susumu Hirano (Japón), Facultad de Estudios Políticos / Profesor, Decano, Escuela de Posgrado de Estudios Políticos, Universidad de Chuo (AI R\&D guidelines) (Directrices para la Investigación y Desarrollo de la IA) recordó la Reunión Ministerial de TIC del G7 de abril del 2016 de Takamatsu (Japón). En ese momento, la Sra. Sanae Takaichi, Ministra japonesa de Asuntos Internos y Comunicaciones, propuso que los países del G7 dirigieran los análisis internacionales sobre un marco de referencia internacional no obligatorio para el desarrollo de IA, con base en un conjunto de Principios de Investigación y Desarrollo de IA que desarrolló su Ministerio. El Ministerio japonés de Asuntos Internos y Comunicaciones (MIC) había creado en ese momento una "Conferencia hacia una Sociedad de Red con la IA" en octubre del 2016 para desarrollar las "Directrices de Investigación y Desarrollo de la IA" propuestas.

Presentó las directrices de julio de 2017 que disponen 9 principios que los investigadores y los desarrolladores de los sistemas de IA deberían seguir:

- Con la finalidad de promover los beneficios de los sistemas de IA: $i$ ) colaboración;

- Para mitigar los riesgos de los sistemas de IA: ii) transparencia, iii) controlabilidad, iv) protección, v) seguridad, vi) privacidad, y vii) ética;

- Para alentar la aceptación por parte de los usuarios y otras partes interesadas: viii) asistencia al usuario y $i x$ ) responsabilidad.

$\mathrm{Su}$ objetivo general es lograr una sociedad enfocada en los humanos, equilibrar los beneficios y riesgos de las redes de IA, garantizar la neutralidad tecnológica y evitar la carga excesiva en los desarrolladores. Para este efecto, el MIC tiene como objetivo que las Directrices se vuelvan reglas no obligatorias y no vinculantes y las mejores prácticas entre las partes interesadas a nivel internacional, y que se revisarán de forma constante y con modificaciones flexibles conforme resulte necesario. 
Cédric Villani (Francia), diputado del movimiento La República en Marcha (LREM) de Effonne, encargado de la misión de IA (Panorama general de la iniciativa de políticas para IA en Francia) dijo que el Presidente le había encomendado recomendar políticas de IA al gobierno francés y a Europa, donde la exigibilidad del RGPD iniciaría en 2018. La primera meta de la misión consiste en mejorar el atractivo y el desempeño de Francia y Europa; la segunda en considerar la imparcialidad y las conexiones sociales. Dijo que la situación debe ser más equilibrada y resaltó las preocupaciones del flujo de investigadores e ingenieros de Europa a otras regiones, y del sector público al sector privado.

El Sr. Villani compartió las conclusiones preliminares de que:

i. La IA es transversal, requiere de amplia participación de toda la sociedad en un debate público sobre la IA;

ii. Las tecnologías de IA actuales dependen del uso de datos. La protección de los datos, la reglamentación de los datos y la economía de los datos son temas complejos de índole legal, cultural y técnica. Las compañías que se dedican a la recolección de datos deben respetar la voluntad europea de proteger la privacidad en cada etapa del proceso;

iii. La necesidad de Europa de ser más competitiva y de contar con más redes para atraer a los escasos recursos humanos, en particular a economistas, matemáticos y estadísticos que puedan desarrollar, programar y utilizar la IA de maneras innovadoras.

Al cierre, habló sobre las muy variadas predicciones de los economistas y sobre que, aunque la IA simplemente hacía correlaciones, él consideraba que el futuro involucraría modelos y causalidad.

Xiao Zhang (China), Vicedirector, China Internet Network Information Center (Panorama general de la economía digital y las politicas de IA de China) explicó que tras la fase de aplicaciones de Internet y la fase de Internet móvil, China se encuentra actualmente en la tercera fase de digitalización, la cual es impulsada por el Internet de las Cosas (IoT, por sus siglas en inglés); se espera que la IA integre los datos y sistemas futuros. Explicó que los esfuerzos de digitalización en China se enfocan en el fortalecimiento de: $i$ ) las conexiones de acceso a Internet móvil y a IoT, ii) ecosistemas de plataforma, iii) big data, e iv) inteligencia e Investigación y Desarrollo de IA. Presentó la "Guía de tres años para el Plan de Internet más Inteligencia Artificial (2016-2018)" que se enfoca en: $i$ ) mejorar la capacidad del hardware de IA; ii) ecosistemas de plataformas sólidos; iii) aplicaciones de IA en áreas socioeconómicas importantes; y iv) el impacto de la IA en la sociedad. También presentó la "Directriz para el Desarrollo de la IA" la cual presenta la perspectiva a largo plazo de la IA en China y tiene como objetivo que dicho país se convierta en un centro global de innovación de IA para el 2030.

Pekka Sivonen (Finlandia), Director de Estrategia y Programas de Digitalización, Tekes Innovation Funding Agency, presentó la visión de Finlandia de la sociedad autónoma en los próximos 10 años (Ambitious development programs enabling rapid growth of AI and platform economy in Finland) (Programas ambiciosos de desarrollo que permiten el rápido crecimiento de la IA y la economía de plataformas en Finlandia). Presentó las estrategias nacionales de Finlandia para el desarrollo de una economía de plataformas y para la IA: Finlandia tiene como objetivo desarrollar una sociedad segura y democrática con IA, que pueda ofrecer los mejores servicios públicos en el mundo y para que la IA brinde una nueva prosperidad, crecimiento y productividad a los ciudadanos. Explicó que Finlandia tiene como objetivo tomar un enfoque integral ante la IA y la economía de plataformas en donde cada parte de la cadena de valor interactúe con la otra; impulsado por el internet, el 
blockchain (cadena de bloques), la IA y las nuevas tecnologías de visualización. Finlandia cuenta con unas 250 compañías que trabajan en desarrollo de IA.

Marten Kaevats (Estonia), Asesor Digital Nacional, Oficina del Gobierno de Estonia, ofreció un resumen general de la implementación de la IA en Estonia (Estonia's ideas on legalising AI) (Las ideas de Estonia sobre la legalización de la IA). Mencionó que Estonia de manera constante analiza nuevas ideas de gobierno electrónico (e-government) que le permitan ahorrar costos y mejorar la eficiencia, por ejemplo, al basar todos los sistemas informáticos gubernamentales del país en cadenas de bloques desde el año 2012. Estonia ya planea el siguiente paso de su sistema de governanza electrónica que utiliza IA y también experimenta con atención médica electrónica (e-healthcare) y la concientización de circunstancias. El enfoque del análisis estonio se centra en la mejora de las vidas y las ciudades, así como en respaldar los valores humanos, con un enfoque en la ética y la responsabilidad. Por el lado de la exigibilidad, Estonia se centra en los valores nucleares de la ética, la responsabilidad, la integridad y la rendición de cuentas y está formando un sistema de exigibilidad con base en cadenas de bloque que mitiga los riesgos de integridad y responsabilidad, con un proyecto piloto planeado en 2018.

Con "StreetLEGAL", los automóviles autónomos se pueden probar en las carreteras estonias desde marzo del 2017. Estonia también es el primer y el único gobierno que actualmente estudia la legalización de la IA; es decir, dar derechos representativos, y responsabilidades, a los algoritmos para comprar y vender servicios en representación de sus propietarios. El gobierno considera varias opciones y tiene como objetivo tener una ley lista para finales de 2018.

Cécile Huet (Comisión Europea), Subjefa de la Unidad, Robótica e Inteligencia Artificial, DG CONNECT, Bruselas, explicó Las iniciativas de la Comisión Europea sobre la IA que tienen como objetivo respaldar el desarrollo de la IA para aumentar la eficiencia y la flexibilidad, facilitar la interacción y la cooperación, mejorar la productividad, la competitividad y el crecimiento, así como mejorar la calidad de vida de los ciudadanos en el empleo y el hogar. Dijo que la Comisión Europea intentaba superar barreras para la utilización de la IA relacionadas con: i) los problemas de desempeño tecnológico, al financiar los programas de robótica e IA de la UE dentro del proyecto "Horizon 2020" (EUR 700 millones para robótica, EUR 20 millones para el proyecto piloto del IoT sobre vehículos autónomos y EUR 20 millones para el desarrollo de una plataforma de IA por demanda); ii) los problemas éticos, legales y sociales relacionados con la seguridad, la responsabilidad, la protección y la propiedad de datos, así como el empleo. La Comisión evalúa las Directivas existentes sobre la Responsabilidad por Maquinarias y Productos para la seguridad y responsabilidad relacionada con la IA, asimismo apoyará los esfuerzos de normalización a través de una experimentación de banco de prueba; iii) la aceptación pública, por ejemplo, los laboratorios abiertos al público de la "Semana Europea de Robótica". Vio con buenos ojos la cooperación adicional con la OCDE en temas comunes.

El análisis se enfoca en identificar las coincidencias y las diferencias entre las políticas, y su función, para beneficiarse de la IA mientras que se abordan los retos. En los enfoques de las políticas hacia los sistemas de IA:

- Todas las estrategias y las iniciativas presentadas tienen como objetivo fomentar el crecimiento, la productividad y la competitividad.

- Hubo un amplio consenso en que los sistemas de IA deben "centrarse en los humanos" y que se requieren decisiones colectivas y sociales en torno a los valores y las opciones que deben guiar los sistemas de IA. También hubo un acuerdo sobre la necesidad de 
desarrollar principios que ayuden a los desarrolladores e investigadores a crear sistemas seguros e imparciales.

- Los diferentes sistemas jurídicos, culturas y contextos políticos juegan un papel crítico, ya que los sistemas de IA se integran a las industrias, los sistemas de atención médica, los sistemas educativos, etc., existentes.

- El acceso a los datos y la propiedad de ellos para la IA es un tema crucial y delicado.

O Conforme el RGPD sea implementado a lo largo de Europa durante 2018, la complejidad de los temas de los datos personales y la vida privada en Europa agudiza la precaución y estimula el debate público.

○ Países como Finlandia y Estonia avanzan rápido. Estonia considera que los ciudadanos son propietarios de sus datos mientras que los gobiernos y las sociedades solo prestan el servicio de mantener los datos. La estrategia finlandesa considera que los ciudadanos deben ser propietarios de los datos que se recopilan a través de sus equipos. Más países, por lo general nórdicos, tienen como objetivo aprovechar la estructura y las políticas de "mydata.org" y crear un mecanismo para que las personas se beneficien de sus datos y los moneticen de manera segura.

O En Europa podrían aprovecharse los modelos de gobernanza de "datos comunes" para ayudar a gestionar los flujos de datos públicos, privados y de otros tipos.

Los participantes también enfatizaron:

- La tensión entre, por un lado, la escala en los negocios de plataforma y, por el otro, la competencia efectiva y la disminución de barreras para el acceso.

- Las funciones de las distintas partes interesadas y de cooperación internacional:

- La función clave de los gobiernos y las organizaciones intergubernamentales en áreas como el establecimiento o la codificación de las reglas del juego, en relación con los impactos sociales y económicos, la planeación de la cooperación a largo plazo e internacional.

$\bigcirc$ La función de convocatoria de los gobiernos para reunir a todas las partes interesadas y para garantizar que el desarrollo de la IA sea inclusivo.

$\bigcirc$ La cooperación internacional a un nivel regional, por ejemplo, entre los países nórdicos, a nivel europeo, en particular con la CE y a nivel internacional, por ejemplo, con la OCDE. También se mencionó la coordinación entre diferentes organizaciones y con China.

O La necesidad de colaborar en desarrollo a futuro de la IA, por ejemplo, para desarrollar un laboratorio con estructura similar al de la "Organización Europea de Investigación Nuclear (CERN) para IA.

La participación en análisis sobre el uso de la IA para abordar los problemas globales como los ODS y los cambios climáticos.

\section{SESIÓN 6: EMPLEO Y HABILIDADES}

Mark Keese, Jefe de la División sobre Habilidades y Empleabilidad de la OCDE, presentó la sesión sobre trabajos y habilidades en la que mencionó que el crecimiento exponencial de las capacidades y la aplicabilidad de la IA deben mejorar la eficiencia con la cual se producen los bienes y servicios. En igualdad de condiciones, la IA, por lo tanto, deberá mejorar la experiencia de todos ya que aumenta la productividad y los precios bajan. Sin embargo, también surgen inquietudes sobre la automatización del trabajo 
y la posibilidad del desempleo tecnológico, así como sobre su impacto en la reducción de los salarios de los trabajadores que están en mayor riesgo de ser desplazados. Explicó: "algunos analistas han planteado la posibilidad de que dejemos de existir como producto de nuestro desarrollo de IA cada vez más poderosa. Pero una preocupación más inmediata es si estamos corriendo el riesgo de quedarnos sin empleos a causa de nuestros inventos".

Stuart Elliot, Director del Consejo de Pruebas y Evaluaciones, United States National Academy of Science (Academia Nacional de Ciencias de Estados Unidos), detalló su investigación para estimar la medida en la que las tecnologías actuales pueden responder preguntas de alfabetización y capacidad numérica de la Evaluación de Competencias de Adultos (PIAAC) de la OCDE (AI and the future of skill demand) (La IA y el futuro de la demanda de habilidades). Su investigación sugiere que actualmente apenas el $11 \%$ de los adultos están arriba del nivel que la IA está cerca de reproducir en términos de las habilidades de alfabetización. Aunque hay cosas que la IA aún no puede hacer, enfatizó que muchas personas tampoco pueden hacerlas. Durante el análisis, también advirtió a los participantes sobre la dificultad de diseñar políticas educativas para llevar al $80 \%$, o incluso al $50 \%$ de los adultos arriba del nivel informático actual y sugirió nuevas herramientas e incentivos para promover las competencias en adultos o la combinación de políticas sobre capacidades con otras intervenciones, incluidos la protección y el diálogo sociales.

Frank Levy, Profesor Emérito Rose, Massachusetts Institute of Technology, añadió a estas preocupaciones (Computadoras y populismo). Sostuvo que al enfocarse en aquello que la IA podría hacer en el largo plazo, nos arriesgamos a no atender lo que ocurre en el corto plazo. Sin duda, a aquellas personas con ocupaciones que requieren habilidades menores o medias que involucran cantidades importantes de repetición ya ha sido afectados por la tecnología y siguen siendo los que están en el mayor riesgo de perder sus empleos. A lo largo de muchos países, los mercados laborales se han polarizado, con partes de trabajos que requieren tanto habilidades menores como elevadas que aumentan mientras que cae la parte de los trabajos que requieren habilidades medias, rutinarios. Dicha turbulencia en el mercado laboral podría ocasionar graves reacciones políticas, sostiene el Profesor Levy, e impactar la adopción de la IA y la respuesta política a la misma.

Christina Colclough, Asesora Sénior en Política, UNI Global Union, recordó que nada es inevitable con respecto a cómo y cuándo se adopta la IA (Putting people and planet first: ethical AI enacted) (Poner a las personas y al planeta primero: decreto para una IA ética). Advirtió sobre el "determinismo tecnológico" e instó a los colaboradores sociales a hablar de y acordar sobre el tipo de futuro que deseamos. Presentó los 10 principios rectores de UNI sobre el mundo futuro del trabajo, la privacidad y la protección de los datos de los trabajadores, y sobre la inteligencia artificial ética. Los principios rectores de UNI para la IA son los siguientes: i) los sistemas de IA deben ser transparentes; ii) los sistemas de IA deben estar equipados con una "caja negra ética"; iii) la IA debe servir a las personas y al planeta con códigos de ética para el desarrollo, aplicación y uso de la IA; iv) adoptar un enfoque con los humanos al mando, con un desarrollo responsable, seguro y útil de la IA; v) asegurar una IA sin género y sin tendencias; vi) compartir los beneficios de los sistemas de IA; vii) asegurar una transición justa y garantizar el respaldo de las libertades y derechos fundamentales; viii) establecer un mecanismo global de gobernanza; $i x$ ) prohibir la atribución de la responsabilidad a robots; $y, x$ ) prohibir la carrera armamentista con IA.

Young Tae Kim, Secretario General, Foro Internacional de Transportes (ITF) (New transport for the new digital age) (Nuevos transportes para la nueva era digital) afirmó que la "gente tiende a enfocarse en la destrucción de los empleos en lugar de en su creación", y enfatizó que aunque la IA podría quedar a cargo de algunas tareas y trabajos, también crearía un gran número de nuevos empleos. Subrayó las oportunidades en términos de seguridad, 
costo, sustentabilidad e inclusividad al utilizar los sistemas de IA en los transportes. También señaló los retos de los conflictos entre los modos de transporte existentes y nuevos (sistema de licencias, influencia política, etc.), la necesidad de las instituciones de evolucionar y las cuestiones éticas. Con respecto a los camiones autónomos, señaló las posibles respuestas propuestas por el sistema de permisos temporales del ITF para gestionar la transición: requerir temporalmente permisos para los camiones autónomos a fin de tener una clase de control sobre el índice de uso de esta clase de camiones; así como utilizar los ingresos derivados de la venta de permisos para financiar los esfuerzos para capacitar nuevamente.

James Hairston, Jefe de Políticas Públicas, Oculus VR, Facebook (AI, employment, and general purpose technologies) (IA, empleo y tecnologías multiusos) ofreció un panorama general del uso de la IA en Facebook, en particular: $i$ ) el aprendizaje automático que permite a las computadoras aprender y resolver problemas de los datos sin una programación explícita; ii) la visión artificial que permite a las computadoras comprender el contenido visual como las imágenes y videos, así como reconocer rostros; y iii) el Procesamiento de lenguajes naturales (NPL, por sus siglas en inglés) que permite a las computadoras leer y comprender texto. Clasificó las aplicaciones de IA en áreas de i) percepción, ii) comprensión y aprendizaje, iii) predicción, y iv) planeación. Subrayó que la IA no es solo una tecnología de remplazo, sino también de complementación y, conforme la población envejezca, podrá ayudar a aumentar la productividad y a brindar educación. También enfatizó que lograr que la IA trabaje para todos requiere la implementación de las políticas correctas y, en particular, invertir en las personas y sus competencias, así como facilitar la movilidad laboral para que las personas puedan aprovechar las oportunidades.

\section{SESIÓN 7: PRIVACIDAD Y SEGURIDAD}

Katarina de Brisis, Subdirectora General en el Ministerio de Gobierno Local y Modernización, Noruega; Presidenta del Grupo de Trabajo sobre Seguridad y Privacidad en la Economía Digital de la OCDE, subrayó la naturaleza de uso dual de la IA que puede tanto ayudar a combatir los delitos informáticos como causar daños cuando se desarrolla y aplica con intenciones nefastas. Advirtió sobre una carrera armamentista entre gobiernos, empresas y agentes malintencionados. Enfatizó que la IA se alimenta de datos, muchos de los cuales son datos personales que pueden agregarse y anonimizarse, pero que proporcionan conocimiento importante sobre las personas.

Peter Fleischer, Consejo de Privacidad Global, Google, (Privacy and AI: designing machine learning systems to respect privacy) (Privacidad e IA: diseño de sistemas de aprendizaje automático que respeten la privacidad), afirmó que la IA requiere: $i$ ) recursos computacionales, ii) datos de capacitación, iii) algoritmos y herramientas, y iv) creatividad e ingenuidad. Mencionó que, aunque la creatividad e ingenuidad humana progresan más lentamente que los otros factores, pueden alcanzar un progreso sorprendente con los recursos computacionales, los datos de capacitación y las herramientas que tienen algoritmos cada vez más poderosos. Enfatizó que la IA actual es capaz de comprender una foto compleja como la de un maratón, pero también las emociones de las personas, lo cual conlleva implicaciones importantes para la privacidad. Al recordar la continua importancia del marco de referencia de privacidad de la OCDE, sostuvo que también aplica en la era de la IA, pero que se requiere atención y escrutinio en: $i$ ) la creación de perfiles y en la clase de perfiles que son aceptables, y quién los realiza; ii) la toma de decisiones automatizada y qué tipos de decisiones pueden confiarse solo a las máquinas; y iii) detección y corrección de las tendencias algorítmicas que vienen a menudo de los datos de capacitación.

Taylor Owen, Profesor Auxiliar de Asuntos de Globales y Medios Digitales, Universidad de Columbia Británica (Governing digital infrastructure) (Regir la infraestructura 
digital), advirtió a los participantes que la IA facilita la desinformación en las plataformas de redes sociales que dependen de la IA (p. ej., algoritmos de servicio de noticias (newsfeed), así como la recolección y monetización de datos a gran escala. Afirmó que la plataforma y los agentes de datos (data brokers) externos usan los perfiles detallados de los usuarios, junto con sus estados de ánimo y deseos inferidos para ofrecerles bienes y contenidos personalizados para lucrar, de manera impredecible y con sesgos. Desde su punto de vista, los microobjetivos automáticos de los algoritmos, junto con los perfiles de datos personales fragmentan la conversación colectiva y se facilita la proliferación y la monetización de la desinformación. Señaló los retos de la gobernanza: $i$ ) los espacios públicos son dominados por las empresas privadas cuyos intereses pueden o no alinearse con los intereses públicos, y ii) los gobiernos no están suficientemente equipados para regular las plataformas grandes, complejas y que evolucionan de manera rápida, como los anuncios de candidatos a puestos de elección popular que tienen varios anuncios simultáneos con microobjetivos. Lanzó un llamado a contar con una gobernanza y una supervisión de los algoritmos que permita combatir la desinformación.

Mathias Cellarious, Funcionario de Protección de Datos y Privacidad, SAP (IA: retos y oportunidades para la protección de datos) enfatizó la falta de concordancia entre las metas encontradas de: i) beneficiarse de manera efectiva de las tecnologías de IA impulsadas por datos y los modelos comerciales; mientras ii) se observan los principios tradicionales de protección de datos en la especificación de propósito, la minimización de datos y la limitación de uso. Subrayó que la IA requiere acceso a grandes cantidades de datos de alta calidad, pero muchos de estos datos podrían clasificarse como datos personales conforme al nuevo alcance extendido del Reglamento General de Protección de Datos (RGPD) de la UE, lo que pone a las compañías y autoridades en una posición difícil.

Planteó que Europa debería enfocarse en salvaguardar el derecho de los individuos a determinar las pautas que regirán su información personal y desaconsejó la implementación del RGPD con un enfoque uniforme, ya que eliminar cada riesgo remoto de privacidad podría poner en juego usos valiosos de datos a cambio de pequeñas ganancias en términos de privacidad. Mencionó que los enfoques previstos conforme al RGPD, en particular la seudonimización, la valoración del impacto en la privacidad y la privacidad por diseño, podrían reducir el impacto del uso de los datos personales en la privacidad, así como permitir la utilidad de los datos mientras que se brinden controles significativos de los datos personales a los usuarios.

Kenneth Cukier, Editor Sénior, The Economist, Reino Unido (Do privacy laws obstruct beneficial uses of data?) (¿Las leyes de privacidad obstruyen los usos beneficiosos de los datos?), recordó que las Directrices de Privacidad de la OCDE se publicaron por primera vez en 1980, una era diferente. También dijo que la IA y el aprendizaje automático cuestionaban los principios de la limitación de recolección (ya que más datos podrían generar más beneficios), la especificación de propósito (al no permitir nuevos usos provechosos de datos que se desconocen en el momento de la recolección) y la limitación de usos (por qué deberían destruirse los datos recolectados después de su uso si la reutilización posterior de los datos con nuevas técnicas podría generar beneficios).

Mencionó que las reglas de privacidad vigentes pueden evitar usos provechosos de datos; por ejemplo, al evitar el uso de las historias médicas electrónicas para predecir quién podría contagiarse de una enfermedad infecciosa. Su propuesta consistió en cambiar el enfoque regulatorio de la recolección al uso de los datos; desarrollar instituciones y prácticas para compartir y analizar datos; aceptar que las protecciones como la anonimización serán imperfectas; sancionar a las entidades que no procesen los datos personales para un beneficio social claro; y desarrollar "estrategias nacionales de privacidad". 
Durante el debate, Marc Rotenberg subrayó la importante distinción entre i) los datos que no tienen contenido personal y sin consecuencia de privacidad y que se agregan y anonimizan, en áreas como el cambio climático y el desarrollo educativo; y ii) los datos que tienen consecuencias de privacidad cuando se procesan, por ejemplo, los datos que se utilizan para realizar determinaciones crediticias. Recordó que la preocupación principal en la protección de datos es el procesamiento razonable de la información sobre los individuos; para que cuando se realice una determinación, los individuos conozcan su base, los factores contribuyentes y puedan objetar si la determinación es incorrecta. Enfatizó la necesidad de la transparencia algorítmica para establecer la responsabilidad de la toma de decisiones con base en computadoras. Al dictar condenas a través de IA, la base para una determinación es una IA opaca.

Hubo un amplio consenso durante el debate en torno a que la gente debe ser capaz de comprender qué pasa con sus datos, el propósito del procesamiento, y con respecto a que las máquinas y los algoritmos deberían estar bajo el control de seres humanos. Los ponentes mencionaron que la tecnología de IA actual puede permitir que los datos anonimizados que se separaron de la identificación original, se vinculen de nuevo a los individuos. También se enfatizó la necesidad de la seguridad de los datos personales que se recolectan y almacenan.

\section{SESIÓN 8: SEGURIDAD, RESPONSABILIDAD Y REPONSABILIDAD ANTE TERCEROS}

Wonki Min, Presidente, CDEP de la OCDE, Corea, abrió la sesión para enfocarse en cuestiones sobre seguridad, responsabilidad legal y de cualquier otra índole que surgieron de la toma de decisiones automatizada impulsada por IA como los vehículos autónomos y otras máquinas del IoT y la "explicabilidad".

Rod Freeman, abogado de productos internacionales, Socio en Cooley, Reino Unido (Evolution or revolution? The future of regulation and liability for AI) (¿Evolución o revolución? El futuro de la regulación y la responsabilidad de la IA), enfatizó que los diferentes tipos de aplicaciones de la IA requerirán diferentes tipos de políticas, respuestas jurídicas y regulatorias que sean flexibles y adaptables y que, por lo tanto, sean adecuadas para el fin a largo plazo y que consideren los beneficios de la IA junto con los riesgos. El Parlamento Europeo condujo una encuesta sobre el futuro de la robótica gracias a la cual se descubrió que hay un amplio consenso sobre la necesidad de una respuesta política y regulatoria para la IA. Recordó que la reglamentación de productos generalmente se basa en la "Responsabilidad del Usuario" a través de la cual el vendedor certifica la seguridad. Pero las aplicaciones de la IA actuales o previstas cuestionan cada vez más este modelo y la sociedad debe decidir sobre el régimen de responsabilidad aplicable a la IA.

Hans Ingels, Jefe de Unidad, Política de Mercado Común, Reconocimiento Mutuo y Vigilancia, Comisión Europea, DG GROW (Artificial intelligence and EU product liability law) (Inteligencia Artificial y la ley de responsabilidad por productos defectuosos de la UE), presentó el reglamento europeo sobre seguridad y responsabilidades por productos. La Directiva de Responsabilidad por Productos Defectuosos (Directiva 85/374/ CEE) de 1985 establece el principio de "responsabilidad sin culpa", es decir, si un producto defectuoso causa daños a un consumidor, el productor podrá ser responsable incluso sin negligencia o culpa de su parte. La Comisión Europea está evaluando si la Directiva aún es adecuada para este efecto en la era de la IA. De manera preliminar, los fabricantes y las aseguradoras parecer estar satisfechos con ello mientras las asociaciones de consumidores consideran que la carga de presentar pruebas de defectos es demasiado pesada. Existen preguntas sobre cómo los conceptos del "producto" y "defectuosidad" aplican a la IA, sobre si la IA es un producto de software, sobre la responsabilidad de los productores y 
sobre la carga de prueba de la parte lesionada. La Comisión planea publicar los informes de la política de la IA en 2018 y crear un paquete de consideraciones sobre políticas que examinen los temas de seguridad y responsabilidad de forma integral.

Pierre Chalançon, Presidente del Grupo de Trabajo para el Consumidor de BIAC (Comité Consultivo Empresarial e Industrial, por sus siglas en inglés) y Vicepresidente de Asuntos Regulatorios, Vorwerk \& Co KG, Representación de la UE (La ciencia ficción no es un fundamento sólido para legislar) primero subrayó la visión de la comunidad de negocios de que los análisis sobre las reglas de seguridad y responsabilidad por los productos de IA deberían enfocarse en los desarrollos de tecnología actuales y previstos y no en la ciencia ficción. Dijo que las empresas estaban satisfechas en términos generales con las reglas europeas en materia de seguridad de productos y de responsabilidad por productos defectuosos, aunque las normas de seguridad, por ejemplo, podrían mejorarse. En la industria de los electrodomésticos, las anticuadas normas de seguridad se enfocan en el hardware y no en el software, y regulan "productos terminados" mientras que los electrodomésticos cada vez más toman decisiones de forma autónoma o semiautónoma. Si un producto es una combinación de hardware y software, la seguridad de un producto podría requerir una revaloración cada vez que se actualice el software. En relación con la responsabilidad por los productos defectuosos, las empresas consideran que el fabricante que coloca los productos terminados en el mercado debe ser responsable de las partes tanto de hardware como de software. También enfatizó que la seguridad informática podría afectar la seguridad de los productos si los productos conectados no son suficientemente seguros y, por ejemplo, los hackers toman control de ellos a distancia y cambian las configuraciones.

Georg Borges, Profesor, Facultad de Derecho, Universidad de Sarre,Alemania (Liability for machine-made decisions: gaps and potential solutions) (Responsabilidad legal por la toma de decisiones de las máquinas: brechas y posibles soluciones), afirmó que el sistema de responsabilidades debe evolucionar para tomar en cuenta las decisiones que toman las máquinas. En el sector automotriz, por ejemplo, el conductor humano es responsable de los daños causados por el automóvil conforme a un esquema de responsabilidad con base en la culpa de la Ley de Responsabilidad Civil por Actos Ilícitos tradicional. Sin embargo, un simple pasajero de un automóvil autónomo no puede ser culpable o haber incumplido su obligación de prudencia. Mencionó que algunas personas sugieren que el "tutor registrado" podría asumir la responsabilidad de los vehículos autónomos, pero que el "tutor" debe ser capaz de controlar el riesgo, lo cual el guardián no puede hacer con los vehículos autónomos.

Concluyó que las acciones autónomas de las máquinas no están cubiertas en los esquemas actuales de responsabilidad con base en la culpa y que, con base en la controlabilidad de riesgo, la responsabilidad objetiva debería ser asignada a los fabricantes. Propuso que un sistema de seguros cubra la brecha de responsabilidad para los sistemas autónomos. El Parlamento Europeo, por ejemplo, presentó la idea del registro obligatorio de máquinas autónomas para crear un esquema de seguros: con base en la valoración de riesgos, las máquinas autónomas registradas se clasificarían, aclarando quién asume el riesgo que generan y quién es responsable como resultado del sistema de seguros. Mencionó los retos para desarrollar un sistema de responsabilidad apropiado para las decisiones que toman las máquinas: $i$ ) los destinatarios de la responsabilidad (tanto fabricantes como usuarios, porque ambas partes podrían contribuir a la seguridad de las máquinas autónomas); ii) el principio de responsabilidad (responsabilidad objetiva con un sistema diferenciado de seguros); y iii) la exigibilidad y carga de desahogo de pruebas.

El análisis enfatizó:

- Un consenso sobre la necesidad de cooperación y diálogo internacionales, en particular entre los encargados de las regulaciones, para involucrar a todas las partes 
interesadas. En alguna medida, las compañías privadas desarrollan políticas reales de IA. La "corregulación" que se implementa en el área de la política de ciberseguridad en Alemania se brindó como un ejemplo de gobernanza efectiva: la industria sugiere las normas de seguridad y si la agencia federal las considera apropiadas, se vuelven un mecanismo de protección para la industria.

- La necesidad de un enfoque integral que considere la seguridad, la responsabilidad, así como las implicaciones de ciberseguridad de la IA.

- La importancia de basar los análisis en tecnología real o prevista.

- La necesidad de equilibrar el campo de juego y garantizar que los sistemas autónomos tengan la responsabilidad monetaria comparable con, por ejemplo, un conductor discapacitado.

\section{SESIÓN 9: TRANSPARENCIA, SUPERVISIÓN Y ÉTICA}

Douglas Frantz, Secretario General Adjunto, OCDE, subrayó la importancia, urgencia y complejidad de desarrollar políticas inteligentes que garanticen la transparencia, supervisión y ética de la IA y mencionó que las opciones de gobernanza van desde la autorregulación a la regulación gubernamental o incluso un tratado internacional.

Konstantinos Karachalios, Director General de la Asociación de Normas del IEEE (Instituto de Ingeniería Eléctrica y Electrónica, por sus siglas en inglés) (The role of technical communities in making intelligent technologies work for the benefit of humanity) (El papel de las comunidades técnicas en hacer que las tecnologías inteligentes trabajen para el beneficio de la humanidad), presentó la Versión 2 del "Diseño Ético de Sistemas Autónomos e Inteligentes (SIA)" con orientación a la práctica del IEEE para recibir comentarios y subrayó la obligación de la comunidad técnica de autorreflexionar, aprender de otros, participar en un diálogo global democrático y construir puentes para la colaboración a nivel internacional, nacional y regional. La serie de normas P-7000 pretende enseñar a los tecnólogos a tomar en cuenta los aspectos contextuales como los valores éticos en la fase de diseño de los sistemas.

Enfatizó, primero, los retos de un ritmo tan veloz de evolución tecnológica que los procesos políticos no pueden seguirle el paso, y la ley no puede aplicarse de manera correcta, lo cual es una amenaza a la democracia. En segundo lugar, dijo que existe un enfoque erróneo sobre la singularidad / superinteligencia porque los modelos de control de datos y de datos de terceros de los gigantes de la tecnología o gobiernos son la amenaza verdadera, y política, para la humanidad. En su opinión, las personas deben recuperar el control sobre sus datos y evitar que los controlen y que sean muy altos los intereses de la democracia, la libertad política y la autodeterminación. Tercero, subrayó la necesidad de medir el impacto del SIA en el bienestar más allá de los ingresos o el PIB, basándose en conceptos como el Índice de una Vida Mejor de la OCDE.

Tomando en cuenta que estos desafíos también son oportunidades, enfatizó la necesidad de que los actores políticos reclamen su territorio con la ayuda de los tecnólogos, para garantizar que el SIA sirva a la humanidad -en términos de bienestar, autodeterminación y el planeta. Todas las partes interesadas deberán empezar a trabajar donde podamos y empezar ahora. El IEEE invita a una autorreflexión a gran escala dentro de la comunidad técnica-científica. Ofreció la asesoría y la asistencia técnica del IEEE a los legisladores y, a su vez, buscó la asesoría de los legisladores también para ayudar a los tecnólogos a comprender las implicaciones sociales y políticas del desarrollo tecnológico. 
Joanna Bryson, Profesora Adjunta en la Universidad de Bath, y Socia del Centro de la Política de Tecnología de la Información en la Universidad de Princeton (Current and potential impacts of artificial intelligence and autonomous systems on society) (Impactos actuales y posibles de la inteligencia artificial y los sistemas autónomos en la sociedad) definió la inteligencia como hacer lo correcto en el momento correcto. Dijo que la IA es un artefacto que los humanos crearon de manera deliberada, por el que alguien es responsable y que involucra cálculos (un proceso físico que requiere energía, tiempo y espacio). Mencionó que el primer artefacto de IA en la historia humana fue la escritura como una forma de conservar ideas que desencadenó el desarrollo exponencial del ser humano, esa inteligencia permitió la comunicación y la agilidad, así como el descubrimiento de nuevos equilibrios de los beneficios mutuos. Dijo que la IA está difuminando la distinción entre el cliente y el empleado y los servicios "gratuitos" e incrementa nuestra dependencia del intercambio de información. Reduce los costos y las ventajas de la ubicación geográfica, aumenta la desigualdad, y, por lo tanto, la polarización, y la interdependencia trasnacional.

Con respecto a la reglamentación de la IA, advirtió sobre la limitación de las responsabilidades y sobre la creación de incentivos para un código más complejo, al decir que los datos de salida de los sistemas de IA deben regularse en lugar de los sistemas mismos. Debemos cooperar para asegurarnos de que las cosas trabajen más para la gente. Convino sobre la importancia y la complejidad de los temas de control de datos y cuestionó: i) si un país como China puede permitir a los humanos progresar y mantener la dignidad mientras controla las vidas y los datos del pueblo; ii) el papel de la IA para ayudar a los migrantes con la integración y la traducción de idiomas; iii) si las artes y las humanidades pueden permanecer interesadas en los humanos cuando, estos pueden utilizar la IA para buscar cuál es el siguiente paso que seguirán.

Carolyn Nguyen, Directora de Políticas de Tecnología, Microsoft (Designing AI to earn trust) (Diseñar la IA para obtener confianza), enfatizó la necesidad de contar con una amplia disponibilidad de IA para las personas tanto en países desarrollados como en vías de desarrollo, con base en un marco de referencia ético para una IA confiable que incluye los principios de "IA enfocada en los humanos", seguridad, imparcialidad, transparencia, privacidad e inclusividad. Se enfocó en la imparcialidad y la transparencia. Dijo que la imparcialidad implica tratar a las personas de forma equitativa, con respeto y dignidad, aunque el concepto difiere entre países y contexto social o cultural. Postuló enfoques para promover la imparcialidad/combatir los sesgos en la IA: $i$ ) para las decisiones que impactan las vidas de las personas (como dictar sentencias); las calificaciones con base en la IA nunca deben ser el único factor mientras que los usuarios / encargados de toma de decisiones deben comprender sus limitaciones; ii) las organizaciones deben atraer diferentes tipos de talento de IA incluyendo sociólogos, economistas y usuarios, desarrollar técnicas analíticas para detectar tendencias, y iii) desarrollar las directrices para el desarrollo y la utilización de los sistemas de IA.

La transparencia o explicabilidad en los sistemas de IA se refieren a la forma de describir cómo el sistema está capacitado o los procedimientos de desarrollo y utilización de los sistemas en lugar de compartir el código real o los datos reales, para permitir a las personas comprender cómo operan los sistemas y brindar mecanismos de responsabilidad que garanticen el desarrollo de algoritmos precisos e inteligibles. Mencionó que se lleva a cabo la investigación sobre la interpretabilidad y la precisión de los algoritmos en grupos como Imparcialidad, Responsabilidad y Transparencia en el Aprendizaje Automático (FATML, por sus siglas en inglés) donde los sistemas de IA se utilizan como parte de la solución. Enfatizó la importancia de un diálogo de varias partes interesadas para identificar y priorizar los temas y mitigar los riesgos, así como para desarrollar y compartir las mejores prácticas al abordar la transparencia en la utilización del sistema de IA. 
Seán Ó hÉigeartaigh, Director Ejecutivo del Centro de Estudios del Riesgo Existencial de Cambridge, presentó los Principios de Asilomar, un conjunto de 23 principios para el desarrollo seguro y socialmente beneficioso de la IA a un plazo cercano y más largo, que fueron el resultado de la conferencia del Future Life Institute de enero de 2017. Dijo que la conferencia de Asilomar extrajo los principios primarios de los análisis, reflexiones y documentos que produjo el IEEE, la academia y las organizaciones no lucrativas mientras reflexionaban sobre la cultura occidental, en particular en relación con la privacidad y los derechos humanos.

Los temas se agruparon en: i) temas de investigación, que requiere financiamiento para la investigación de la IA beneficiosa que incluye preguntas difíciles de informática; economía, derecho estudios sociales; un "vínculo ciencia-política" constructivo; y una cultura de investigación técnica de cooperación, confianza y transparencia; ii) ética y valores, que requiere que el diseño y la operación de los sistemas de IA sean seguros y confiables, transparentes y responsables, que protejan la libertad, la privacidad, la dignidad humana, los derechos y la diversidad cultural, un amplio fortalecimiento y los beneficios compartidos de los individuos; y iii) temas a plazos más largos, en particular, evitar supuestos fuertes sobre los límites superiores de las capacidades futuras de la IA y la planeación cuidadosa del posible desarrollo de la inteligencia artificial general (IAG).

En el análisis, los participantes convinieron sobre la necesidad de establecer un marco de referencia para las políticas para aclarar los diferentes intereses y objetivos, así como ayudar a guiar el rápido desarrollo de la IA, incluyendo los puntos de referencias básicos y una declaración normativa sobre cómo debe verse una transición de IA exitosa. Enfatizaron la importancia del trabajo conjunto para desarrollar un marco de referencia de la gobernanza y reglas que sean lo suficientemente flexibles, que involucren a todas las partes interesadas y que no repriman la innovación.

El análisis destacó el papel de diferentes partes interesadas en la gobernanza de la IA:

- El papel complementario de gobernanza de los gobiernos que desarrollan políticas relativamente estables y de las organizaciones profesionales de normas como el IEEE que pueden adaptar y actualizar sus normas de manera más frecuente.

- Los estándares técnicos como los del IEEE, que se desarrollaron en procesos voluntarios $\mathrm{y}$ ascendentes, las cuales se describieron como un sistema de gobernanza no normativa que se utiliza si aporta valor.

- La importante función de los esfuerzos autorregulatorios.

- El acuerdo de que la OCDE está bien situada para desarrollar principios para la IA en la sociedad, con base en las Directrices japonesas de Investigación y Desarrollo, la Iniciativa del IEEE, los principios de Asilomar y otros conjuntos de principios como los de ACM.

- La necesidad de garantizar la aplicación del derecho a los sistemas de IA.

- La necesidad de asegurar un campo de juego nivelado para los participantes del sector privado.

- La importancia de involucrar a las partes interesadas de países en vías de desarrollo y considerar las formas para evitar la expansión de la brecha entre lo que se tiene y lo que no.

- Que la IA no sufre y, por lo tanto, no requiere derechos protectores. 


\section{SESIÓN 10: CIERRE Y PASOS SIGUIENTES}

Wonki Min presentó una sesión de enfoque en pequeños resúmenes de los análisis de cada panel, los retos clave de las políticas, las posibles soluciones de las políticas, y las formas para facilitar aún más el diálogo internacional. A esto le siguió una sesión entre grupos de partes interesadas en la que compartieron sus perspectivas. La sesión se enfocó en las oportunidades y los retos claves que presenta la IA y los respectivos papeles de la autorregulación de la industria, las intervenciones de las políticas, la cooperación de diversas partes interesadas y la cooperación internacional.

Kenneth Cukier presentó cinco temas generales abordados en la sesión sobre "El Estado de la Investigación de IA": $i$ ) en general, es probable que las máquinas aumenten las capacidades del ser humano en lugar de que reemplazarlos; ii) la necesidad de seguridad en los algoritmos y de "IA comprobablemente benevolente"; iii) la necesidad de robots con sentidos humanos que les sirvan de manera segura; iv) un ecosistema de IA más amplio y la necesidad de interoperabilidad entre los sistemas de IA; y, v) la creación de datos sintéticos para el algoritmo de aprendizaje automático con base en los modelos del mundo y la posible necesidad de un "CERN para la IA". Desde una perspectiva de políticas, señaló que los avances recientes en la tecnología de la IA nos permiten utilizar los datos en formas fundamentalmente nuevas en comparación a hace algunos años, lo cual causó la necesidad de replantear las políticas públicas con una mentalidad abierta en visión de las tecnologías nuevas.

Andrew Wyckoff resumió la sesión 2 sobre "Las Aplicaciones de la IA y Estudios de Casos". Citó a Garry Kasparov, quien dijo que la IA es una herramienta para expandir el alcance, las facultades y el conocimiento humano y que, a medida que crece su poder, también lo debe hacer la responsabilidad humana. Presentó la IA como una herramienta tecnológica de utilidad general para aplicaciones tan diversas como la construcción de ciudades inteligentes en China, impulsar los vehículos autónomos de BMW, o rastrear los datos de los sensores de las vacas. Recordó que, así como con las GPT (tecnologías de utilidad general, por sus siglas en inglés) anteriores, debemos esperar algunas turbulencias y alteraciones, además de desafíos para las políticas, entre los que se incluyen el hecho de si todas las empresas, incluyendo las PyME, pueden sortear la transición; la equidad y si la IA ampliará la brecha entre los países del norte y el sur, entre las PyME y los negocios grandes y entre las personas, o si brindará oportunidades para dar el salto tecnológico. Google pone a disposición del público una base de datos curada, códigos y capacitación como una forma de divulgar la IA. Una plataforma parecida al CERN, una infraestructura de investigación pública reconocida a nivel mundial que podría compartir el uso de las bases de datos curadas y programas de código abierto, así como brindar capacitaciones, lo cual ayudaría a aliviar el problema.

Claire Jolly, resumió la sesión 3 "Acercamiento a la IA en las Aplicaciones Espaciales" en la que se analizaron los usos geoespaciales emergentes que han sido posibles por la combinación de los datos satelitales y el aprendizaje automático. Reportó que las start-ups presentan formas nuevas y lucrativas de monitorear sectores completos mediante el uso de los datos satelitales y otros datos. El gobierno australiano está utilizando las aplicaciones geoespaciales para monitorear un continente entero y la Comisión Europea explicó que se espera una avalancha de datos satelitales de satélites en nuevas constelaciones. Los retos de las políticas que se identificaron incluyen: i) las políticas de datos abiertos, en particular para que las PyME desarrollen productos y servicios innovadores con valor agregado; ii) la necesidad de mayor interoperabilidad y la normalización de formatos de datos de los satélites; y iii) la siguiente competencia fuerte para contratar personas con las habilidades adecuadas, en especial para las PyME. 
Dominique Guellec resumió la sesión 4 "Mejorar el Descubrimiento - El papel de la IA en la Ciencia" en la que se analizó la promesa de utilizar la IA en las ciencias, a través de laboratorios automatizados, la explotación de enormes cantidades de datos y el uso de "los datos como el modelo". Reportó que, en la práctica, la IA en las ciencias se utiliza para clasificar y limpiar inmensos conjuntos de datos. La IA complementa a los científicos, ya que los humanos están a cargo del pensamiento conceptual como la construcción del marco de referencia de la investigación y el establecimiento del contexto para los experimentos específicos. Los retos para las políticas incluyen la necesidad de: $i$ ) adaptar la educación y capacitar a los científicos para complementar mejor la IA, es decir, ayudar a los científicos a enfocarse en el pensamiento conceptual; y ii) considerar el nivel apropiado de participación de los gobiernos en la investigación de la IA para abordar los grandes retos sociales, aunque las empresas han asumido un papel dominante en la investigación de la IA durante los últimos 5 años.

Anne Carblanc resumió la sesión 5 sobre el "Panorama de la Política de la IA". Las organizaciones no gubernamentales como la Partnership on AI y la Future Society trabajan para crear un ambiente habilitador para la IA para prosperar en una manera ética. El panel mostró las iniciativas nacionales para la utilización de la IA para la competitividad (por ejemplo, en China, la Comisión Europea, Finlandia y Francia), así como las iniciativas para abordar los retos que genera la IA (por ejemplo, Japón, Estonia, Francia o el G7). Las conclusiones de la sesión incluyeron la necesidad de: i) garantizar una "IA enfocada en los humanos", que maximice los beneficios al tiempo que aborda los riesgos éticos, lo riesgos a la privacidad y la transparencia; ii) reconocer las diferencias entre las culturas nacionales, los sistemas jurídicos, los tamaños de los países y el nivel de adopción de IA; y iii) colaboración entre diversas partes interesadas para reducir las barreras al acceso a la IA y los datos (por ejemplo, con una plataforma de colaboración "CERN para la IA" y los "Datos Comunes") y de desarrollar directrices flexibles para la investigación y las aplicaciones de la IA.

Marc Keese resumió la sesión 6 sobre "Empleos y Habilidades", con un enfoque en la relación entre el ser humano y las máquinas. Mencionó hallazgos que señalan que la mitad de las personas en los países miembros de la OCDE tiene un nivel de alfabetización y habilidad numérica que ya alcanzó la IA. Mencionó que su sesión sugería un vínculo entre la IA y la polarización laboral, el crecimiento del populismo y el aumento de la desigualdad. Dijo que los retos del desplazamiento laboral por la tecnología y la globalización, así como la creciente polarización laboral conforme desaparecen los trabajos de la clase media y aumenta la demanda de trabajos con salarios más bajos no solo están relacionados con la IA. También mencionó las oportunidades que ofrece la IA a los trabajadores para hacer su trabajo más interesante al automatizar las tareas rutinarias, lo cual permite un trabajo más flexible y posiblemente mayor equilibrio en la vida laboral. Enfatizó que: i) en lugar de reaccionar a desarrollos específicos de la tecnología, los legisladores deben evolucionar sus políticas para moldear el futuro del trabajo y facultar a los trabajadores individuales a través de acceso a la capacitación y la protección de seguridad social; ii) necesitamos obtener mejores evidencias a través de proyectos como Going Digital y Future of Work; y iii) hay una oportunidad para federalizar las actividades de la OCDE y establecer el debate multidisciplinario de la política sobre la IA.

Katarina de Brisis resumió la Sesión 7 sobre "Privacidad y Seguridad", con un enfoque en: evitar la creación de perfiles no deseados, corregir los sesgos de los algoritmos, insertar los valores humanos en la toma de decisiones automatizada y operacionalizar la transparencia de los algoritmos o la "habilidad de explicarlos". Hizo un llamado a más análisis entre las partes interesadas sobre las plataformas en redes que aplican la IA hoy en día y lo que necesita regularse y cómo. Mencionó que la IA depende de los datos, de los cuales partes 
crecientes pueden asignarse como datos personales (por ejemplo, datos de geolocalización desde sensores). Resaltó la necesidad de monitorear el impacto de las legislaciones como el RGPD, y asegurar su cumplimiento, pero también de diseñar medidas de privacidad que garanticen dicho cumplimiento en el lugar con equipos multidisciplinarios que incorporen la privacidad en las soluciones de IA y que realicen evaluaciones del impacto en la privacidad para equilibrarla con la funcionalidad y la flexibilidad de la tecnología. Recordó la relevancia del trabajo continuo de la OCDE en los principios para un acceso mejorado a los datos para equilibrar el acceso a los datos para beneficiar a la sociedad y ayudar a resolver los retos sociales con doctrinas básicas de privacidad.

Wonki Min resumió la sesión 8 sobre "Seguridad, Responsabilidad y Responsabilidad ante terceros" en la que se examinó la relevancia y la eficacia de los esquemas de seguridad y responsabilidad legal existentes por productos defectuosos al aplicarlos a la IA y a los productos conectados. Dijo que había un consenso sobre la necesidad de llevar a cabo un debate pragmático, inclusivo y que incluya varias partes interesadas de las políticas sobre cómo la IA impacta los conceptos existentes de seguridad y responsabilidad como "producto", "seguridad", "defecto" y "daño", con base en la tecnología de IA actual y prevista. Mencionó que es probable que no haya una solución uniforme para los sistemas autónomos: por ejemplo, los vehículos autónomos parecen desafiar de manera clara los conceptos existentes de la responsabilidad legal con base en la culpa y la responsabilidad objetiva y es probable que los seguros desempeñen un papel clave. También enfatizó la necesidad de considerar los beneficios de seguridad que ofrecen los productos de IA, junto con los riesgos y de nivelar las normas entre los productos con IA incorporada y los productos sin IA.

Douglas Franz resumió la sesión 9 sobre "Transparencia, Supervisión y Ética" en la que se observó un consenso con respecto a la urgente necesidad de conducir una conversación amplia con muchas partes interesadas sobre el futuro de la IA y su implementación, así como sobre la necesidad de garantizar la confianza, igualdad, transparencia y la rendición de cuentas. Mencionó la necesidad de más análisis sobre los modelos de gobernanza más apropiados para la IA y su posible complementariedad, desde las normas y la autorregulación a disposiciones no obligatorias para la regulación. Resaltó las oportunidades para basarse en el conocimiento valioso existente y condensar los mejores principios para las políticas públicas y la cooperación internacional. Citó, por ejemplo, el Diseño Éticamente Alineado del IEEE y sus series de normas, los Principios de Asilomar, y las directrices que desarrolló el Ministerio japonés de Asuntos Internos y Comunicación. Enfatizó la necesidad de que la OCDE tome medidas para convertir la información en principios accionables para las políticas.

Marc Rotenberg, representante del Comité Consultivo de la Sociedad Civil para la sociedad de la información (CSISAC, por sus siglas en inglés) de la OCDE y Presidente del Centro de Información de Privacidad Electrónica (EPIC, por sus siglas en inglés), mencionó que el análisis sobre la IA no se trata solamente de aquellos que diseñan los programas de IA y que crean empresas, sino del impacto mucho más amplio que tiene la tecnología sobre el público y sobre las instituciones políticas y sociales. Afirmó que el camino actual era peligroso e insostenible debido a la creciente polarización y la desigualdad de riquezas que fomenta de manera parcial la tecnología. Hizo un llamado a la OCDE como una organización integrada por países democráticos avanzados para abordar los desafíos públicos vinculados con la IA y la transparencia de los algoritmos para establecer la responsabilidad democrática sobre la innovación, con base en las conversaciones que se iniciaron en Foro Global de Conocimiento en Tokio en 2014. Al decir que la IA, la singularidad y la inteligencia artificial general están acelerando los procesos, enfatizó la urgencia de encontrar soluciones. Citó a Edison: "lo que el hombre crea con las manos, 
debe controlarlo con la cabeza", advirtiendo que las consecuencias de la inacción serían importantes.

\begin{abstract}
Anna Byhovskaya, Asesora de Política, Comité Asesor de Sindicatos ante la OCDE (TUAC), planteó que los Sindicatos deben ser parte del diálogo de las diversas partes interesadas de las políticas sobre la IA, más allá de solo el empleo y las habilidades: los impactos a nivel empresa y a nivel social en las personas y sus preocupaciones. Dijo que los resultados en el mundo real de la IA requieren una política proactiva y un reglamento ex-ante (antes del suceso). Enfatizó que: i) la IA debe estar bajo control humano; ii) los análisis sobre el empleo deben tratar la creación de empleos y cómo la IA se aplicará en el lugar de trabajo y cambiará las tareas de trabajo. Dijo que la OCDE está bien ubicada para facilitar dichos análisis porque tiene los datos y la participación de las partes interesadas y los colaboradores sociales.
\end{abstract}

También buscó respuestas de políticas más fuertes que no individualicen la responsabilidad al tratar el desempleo, los cambios laborales y la reducción de salarios, en especial para personas y trabajadores con niveles de habilidades más bajos, y que creen marcos de referencia de transición laboral para los trabajadores y el análisis sobre el financiamiento y la gobernanza del sistema, así como la consulta de las instituciones sociales. Enfatizó la necesidad de realizar un análisis de los impactos reales de la IA, las preocupaciones del movimiento laboral sobre la concentración del mercado, la propiedad de los datos y los mecanismos de ahorros de costos en los modelos comerciales, así como mecanismos de los patrones para desarrollar las habilidades de los trabajadores, por ejemplo, instrumentos de negociaciones de contratos colectivos, aumentar la productividad contra la autonomía de los trabajadores, y crear reglas sobre la recolección de los datos de los trabajadores.

Nicole Primmer, Directora Sénior de Política, Negocios en la OCDE (BIAC), resaltó las promesas de la IA, pero también los retos debidos a los silos entre varias partes del gobierno, la supervisión de la gobernanza, y el equilibrio del acceso a los datos con privacidad. Enfatizó: i) la colaboración necesaria entre los negocios, el gobierno, la comunidad técnica, la sociedad civil y otras partes interesadas; ii) el análisis sobre las habilidades en la era del IA; iii) las políticas inteligentes para fomentar la innovación y la utilización de la IA y alentar la aplicación responsable de la IA, con base en los marcos de referencia existentes; iv) el uso de la IA entre sectores, sin olvidar las PyME; y $v$ ) distinguir entre los temas a corto, mediano y largo plazo relacionados con la IA. También resaltó que la IA fue un pilar central del trabajo del B20 durante la presidencia alemana del G20, con el apoyo del B20 al trabajo de la OCDE en esta área: i) el diálogo público sobre las oportunidades y los desafíos de la IA, ii) los ecosistemas favorables para la IA, y iii) la facilitación de infraestructura inteligente. El BIAC respalda el trabajo de la OCDE en materia de IA debido a su capacidad interdisciplinaria, el enfoque con base en las pruebas y el enfoque con base en el diálogo.

Clara Neppel, Directora Sénior, Oficina Europea del IEEE, representante del Comité de Asesoría Técnica sobre Internet (ITAC), presentó las actividades del IEEE sobre la normalización y la colaboración para "Avanzar la tecnología para el beneficio de la humanidad" con sus 420,000 miembros a nivel mundial (presentación). Dijo que la IA crea perfiles de las personas con base en la capacitación y en los datos recolectados para hacer determinaciones y sugerencias que deberían ser beneficiosas para la gente. Mencionó que para que los usuarios controlen los datos personales, los agentes que conocen nuestras preferencias podrían negociar el compartir datos complejos con otros sistemas inteligentes. Destacó la necesidad de conjuntos de datos inclusivos y diversos para la IA que puedan expandir los intereses u oportunidades perfiladas del usuario. Tomando en cuenta que se puede alentar el acceso abierto para algunos datos, pero no todos los datos, subrayó la necesidad de diferentes mecanismos de licencias para los datos inspirados, por ejemplo, 
en los términos FRAND (Imparcial, Razonable y No Discriminatorios, por sus siglas en inglés) y para los formatos normalizados de intercambio de datos.

También enfatizó la necesidad de normalizar y certificar los algoritmos, en particular con relación a los sistemas de seguridad y protección pertinentes, pero también para los sistemas que toman decisiones que impactan la vida o la salud de los individuos. Aunque se están registrando patentes para sistemas de IA, los sistemas de autoaprendizaje que se adaptan a su entorno podrían requerir un replanteamiento de los instrumentos de certificación de los sistemas de IA y de los mecanismos para hacer valer los derechos de propiedad intelectual. Un análisis mayor alrededor de la "confianza" también engloba los temas sobre la identidad digital, la inclusión digital y la ética. Cuando hablamos de ética, es necesario pensar a nivel individual, en la educación, así como en los valores incorporados en el diseño del sistema, y ampliar la medida de éxito más allá de las ganancias a fin de incluir a las personas y al planeta.

Joanna Bryson dijo que las políticas deben basarse en aquello que la IA puede hacer actualmente, pero enfatizó el rápido ritmo de cambio del estado actual de la IA. Mencionó que los humanos cambian mucho más lento y creamos la ética para protegernos. Enfatizó la IA enfocada en los humanos, es decir, la construcción de sistemas que sean seguros y se respalden, y que las personas no tienen de qué preocuparse.

El debate se centró en los pasos siguientes que debe seguir la OCDE con respecto a la IA después del Foro de Previsión Tecnológica sobre IA de noviembre del 2016, la publicación de las "Perspectivas de la OCDE sobre la Economía Digital de 2017, y la conferencia. Los participantes hicieron un llamado para una coordinación multidisciplinaria que involucre los grupos que se enfocan en la economía digital, la ciencia, los modelos comerciales, la protección del consumidor, la educación y el empleo, con una visión para desarrollar principios de derecho suave en la forma de una recomendación del consejo, con el objetivo de unas directrices que puedan soportar el paso del tiempo y que sean lo suficientemente flexibles para no dificultar el desarrollo de la IA. También se solicitó que la OCDE ayude a respaldar los análisis de los grupos de los niveles más altos del G7 y el G20. 


\section{Anexo. Agenda de la Conferencia}

Presidente de la Conferencia: Wonki Min, Presidente, Comité sobre Política de Economía Digital (CDEP) de la OCDE, Corea

JUEVES 26 de octubre de 2017 - DESARROLLO Y APLICACIONES DE LA IA, CC 1

\section{9:00 - 9:20 DISCURSO DE APERTURA Y COMENTARIOS DE BIENVENIDA}

Garry Kasparov, Ex Campeón Mundial de Ajedrez y autor de "Deep Thinking" (por video)

Andrew Wyckoff, Director de Ciencia, Tecnología e Innovación (STI, por sus siglas en inglés), OCDE

Masahiko Tominaga, Viceministro para Coordinación de Políticas, Ministerio de Asuntos Internos y Comunicación (MIC), Japón

\section{9:20 - 10:50 1. ESTADO DE LA INVESTIGACIÓN DE LA IA}

Moderador de la sesión: Kenneth Cukier, Editor Sénior, The Economist, Reino Unido

Francesca Rossi, Científica Investigadora, IBM Watson y Profesora de Ciencias Informáticas, Universidad de Padua, Italia

Stuart Russell, Profesor de Ciencias Informáticas, Universidad de California, Berkeley, Estados Unidos.

Rodolphe Gelin, Líder de Ingeniería de Software en Robótica, SoftBank Robotics, París

Osamu Sudoh, Profesor, Universidad de Tokio, Iniciativa Interfacultades en Estudios Informáticos, Japón

Philipp Slusallek, Director Científico en DFKI, Alemania

10:50-11:20 DESCANSO Y DEMOSTRACIONES INTERACTIVAS DE GOOGLE Y FACEBOOK, ATRIO

11:20 - 12:40 2. APLICACIONES DE LA IA Y ESTUDIO DE CASOS

Moderador de la sesión: Andrew Wyckoff, Director de Ciencia, Tecnología e Innovación, OCDE

Valerio Dilda, Socio, McKinsey \& Company, París

Reinhard Stolle, Departamento de Inteligencia Artificial en BMW AG, Múnich

Max Yuan, fundador y presidente, Xiaoi Robot Technology, Shanghái

Lynette Webb, Gerente Sénior, Estrategia de Política Europea, Google, Londres

12:40 - 13:40 COMIDA (Salones Roger Okrent y George Marshall, Château de la Muette)

13:40 - 15:00 3. ACERCAMIENTO A LA IA EN LAS APLICACIONES ESPACIALES

Moderadora de la sesión: Claire Jolly, Jefa del Foro Espacial de la OCDE

Tugdual Ceillier, Científico de Datos en Jefe, EarthCube, Toulouse

Bryan Yates, Director de ventas - región Europa, Oriente Medio y África, Orbital Insight, Mountain View, California

Thanh-Long Huynh, Director General, Quantcube Technology, París

Bahaa Alhaddad, Desarrollo de Negocios Espaciales, Starlab Space, Harwell Oxford, Reino Unido

Alexander Cooke, Consejero, Departamento de Industria, Innovación y Ciencia, Australia

Christophe Roeland, Funcionario de Políticas, Datos Espaciales para los Retos y Crecimiento Sociales, DG GROW, CE, Bruselas

15:00 - 16:20 4. MEJORAR EL DESCUBRIMIENTO - El PAPEL DE LA IA EN LA CIENCIA

Moderador de la sesión: Dominique Guellec, Jefe de la División de Políticas en Ciencia y Tecnología de la OCDE

Stephen Roberts, Profesor de Aprendizaje Automático en Ingeniería Informática, Universidad de Oxford, Reino Unido

Hiroaki Kitano, Presidente y Director General de Sony Computer Science Laboratories, Japón

Ross King, Profesor de Inteligencia Artificial, Facultad de Ciencias Informáticas de la Universidad de Manchester, Reino Unido

Jonathan McLoone, Director Técnico, Wolfram Research Europe 


\begin{tabular}{|c|c|}
\hline 16:20-16:50 & DESCANSO Y DEMOSTRACIONES INTERACTIVAS DE GOOGLE Y FACEBOOK, ATRIO \\
\hline $16: 50-18: 30$ & 5. PANORAMA DE LAS POLÍTICAS DE IA \\
\hline \multicolumn{2}{|c|}{ Moderadora de la sesión: Anne Carblanc, Jefa de la División sobre Política de Economía Digital de la OCDE } \\
\hline \multicolumn{2}{|c|}{ David Heiner, Asesor en Política Estratégica en Microsoft, representante de la Asociación para la Inteligencia Artificial } \\
\hline \multicolumn{2}{|c|}{ Nicolas Miailhe, Director de Inteligencia Artificial, The Future Society @ Harvard Kennedy School of Government } \\
\hline \multicolumn{2}{|c|}{ ITALIA: Benedetta Arese Lucini } \\
\hline \multicolumn{2}{|c|}{ JAPÓN: Susumu Hirano, Facultad de Estudios Políticos / Profesor, Decano, Escuela de Posgrado de Estudios Políticos, Universidad de Chuo } \\
\hline \multicolumn{2}{|c|}{ FRANCIA: Cédric Villani, diputado del movimiento La República en Marcha (LREM) de Effonne, encargado de la misión de IA } \\
\hline \multicolumn{2}{|c|}{ CHINA: Xiao Zhang, Vicedirector, China Internet Network Information Center } \\
\hline \multicolumn{2}{|c|}{ FINLANDIA: Pekka Sivonen, Director, Estrategia y Programas de Digitalización, Tekes Innovation Funding Agency, Finlandia } \\
\hline \multicolumn{2}{|c|}{ ESTONIA: Marten Kaevats, Asesor Digital Nacional, Oficina del Gobierno de Estonia } \\
\hline \multicolumn{2}{|c|}{ COMISIÓn EUROPEA: Cécile Huet, Subjefa de la Unidad, Robótica e Inteligencia Artificial, DG CONNECT, Bruselas } \\
\hline $18: 30$ & ÓCTEL DE RECEPCIÓN (Salones Roger Okrent y George Marshall, Château de la Muette) \\
\hline
\end{tabular}

VIERNES 27 de octubre de 2017 - CONSIDERACIONES DE POLÍTICAS PÚBLICAS QUE SURGIERON POR LA IA, CC12

\section{9:30 - 11:00 6. EMPLEO Y HABILIDADES}

Moderador de la sesión: Mark Keese, Jefe de la División sobre Habilidades y Empleabilidad de la OCDE

Frank Levy, Profesor Emérito Rose, Massachusetts Institute of Technology

Christina Colclough, Asesora Sénior en Política, UNI Global Union

James Hairston, Jefe de Políticas Públicas, Oculus VR, Facebook

Stuart Elliott, Director del Consejo de Pruebas y Evaluaciones, Academia Nacional de Ciencias de Estados Unidos

Young Tae Kim, Secretario General, Foro Internacional de Transporte (ITF)

11:00 - 11:30 DESCANSO Y DEMOSTRACIONES INTERACTIVAS DE GOOGLE Y FACEBOOK, ATRIO

11:30 - 12:30 7. PRIVACIDAD Y SEGURIDAD

Moderadora de la sesión: Katarina de Brisis, Subdirectora General en el Ministerio de Gobierno Local y Modernización, Noruega; Presidenta del Grupo de Trabajo sobre Seguridad y Privacidad en la Economía Digital de la OCDE

Peter Fleischer, Consejero de Privacidad Global, Google

Taylor Owen, Profesor Auxiliar de Asuntos de Globales y Medios Digitales, Universidad de Columbia Británica

Mathias Cellarius, Funcionario de Protección de Datos y Privacidad, SAP

Kenneth Cukier, Editor Sénior, The Economist, Reino Unido

12:30 - 14:00 COMIDA (No se proporcionará comida. Existen varias opciones disponibles en el sitio y alrededor)

14:00 - 15:00 8. SEGURIDAD, RESPONSABILIDAD Y RESPONSABILIDAD ANTE TERCEROS

Moderador de la sesión: Wonki Min, Presidente, CDEP de la OCDE, Corea

Rod Freeman, abogado de productos internacionales, Socio en Cooley, Reino Unido

Hans Ingels, Jefe de Unidad, Política de Mercado Común, Reconocimiento Mutuo y Vigilancia, Comisión Europea, DG GROW

Pierre Chalançon, Presidente del Equipo de Trabajo del Consumidor de BIAC y Vicepresidente de Asuntos Regulatorios, Vorwerk \& Co KG, Representación de la UE.

Georg Borges, Profesor, Facultad de Derecho, Universidad de Sarre, Alemania 


\section{VIERNES 27 de octubre de 2017 - CONSIDERACIONES DE POLÍTICAS PÚBLICAS QUE SURGIERON POR LA IA, CC12}

\section{5:00 - 16:00 9. TRANSPARENCIA, SUPERVISIÓN Y ÉTICA}

Moderador de la sesión: Douglas Frantz, Secretario General Adjunto, OCDE

Konstantinos Karachalios, Director General de la Asociación de Normas del lEEE

Joanna Bryson, Profesora Adjunta en la Universidad de Bath, y Socia del Centro de la Política de Tecnología de la Información en la Universidad de Princeton

Carolyn Nguyen, Directora de Políticas de Tecnología, Microsoft

Seán Ó hÉigeartaigh, Director Ejecutivo del Centro de Estudios del Riesgo Existencial de Cambridge

16:00 - 16:30 DESCANSO Y DEMOSTRACIONES INTERACTIVAS DE GOOGLE Y FACEBOOK, ATRIO

16:30 - 18:00 10. CIERRE Y PASOS SIGUIENTES

Presidente: Wonki Min, Presidente del CDEP

INFORMES BREVES DE LOS MODERADORES DE LAS SESIONES, SEGUIDOS POR PRESENTACIONES Y ANÁLISIS DE LAS PARTES INTERESADAS Marc Rotenberg, representante del Consejo Asesor de la Sociedad de Información de la Sociedad Civil de la OCDE (CSISAC) y Presidente del Centro de Información de Privacidad Electrónica (EPIC)

Anna Byhovskaya, Asesora de Política, Comité Asesor de Sindicatos ante la OCDE (TUAC)

Nicole Primmer, Directora Sénior de Política, Negocios en la OCDE (BIAC)

Clara Neppel, Directora Sénior, Oficina Europea del IEEE, representante del Comité de Asesoría Técnica sobre Internet (ITAC)

Esta traducción fue posible gracias a la gestión de la Asociación Mexicana de Internet, A.C. con el patrocinio de

\section{facebook Google Microsoft}

